Published in European accounting review, 2016, vol. 25, no. 4, pp. 687-718 which should be cited to refer to this work

\title{
Cost (In)Efficiency and Institutional Pressures in Nursing Home Chains
}

\author{
Cécile MARTIN
}

LEDa-LEGOS

Université Paris-Dauphine

Paris

France

\section{Tiphaine JÉRÔME*}

Department of Accounting and Management Control

HEC Paris

Jouy-en-Josas

France

Ecole hôtelière de Lausanne, HES-SO //

University of Applied Sciences Western Switzerland

Lausanne

Switzerland

The paper was accepted for publication in European Accounting Review.

*Correspondence Address: Tiphaine Jérôme, Ecole hôtelière de Lausanne, HES-SO // University of Applied Sciences Western Switzerland, Lausanne, Switzerland. Email: tiphaine.jerome@ehl.ch. Phone number: +41 21 7851777.

Acknowledgments: We are grateful to our anonymous reviewer and the two editors for their helpful suggestions. We wish to thank Mélina Ramos-Gorand for sharing her skills in geography and for providing us with several variables included in this paper. We also thank Karen Earl-Erpelding and Simona Kepalaite for their editing help. The research was carried out at Direction de la Recherche, des Études, de l'Évaluation et des Statistiques (DREES), under a contract "convention prêt de données". It allowed us to access most of data used in this paper. 


\section{Cost (In)Efficiency and Institutional Pressures in Nursing Home Chains}

ABSTRACT Over the past ten years, merger activities in the private for-profit nursing home industry have been increasing in Europe. In this paper, we investigate chain affiliation's influence on the performance of lucrative nursing homes. We measure performance using a cost frontier estimated by stochastic analysis on a sample of 370 French for-profit nursing homes. We find that cost efficiency decreases with the number of facilities in a chain. We also identify different external actor types in nursing homes' institutional environment and test their influence. We show that nursing home chains' cost efficiency improves when local governments and shareholders exert pressure. Our results are robust to alternative model specifications and another definition of costs. Overall, our findings inform researchers, as well as standards setters, of the relevance of chain affiliation and of the role of institutional pressures regarding cost containment at the nursing home level.

Keywords: nursing homes, cost efficiency, chain affiliation, frontier models

JEL Codes: I1, L5 


\section{Introduction}

Cost containment is one of the challenges the health care sector faces (Cardinaels, Roodhooft, \& Van Herck, 2004; Chua \& Preston, 1994). In particular, nursing homes face important pressures to become more cost-efficient, as the long-term care (LTC) sector imposes a major financial burden on states and users. Public expenditures devoted to LTC represent $1.8 \%$ of gross domestic product (GDP) across the European Union in 2010 (Lipszyc, Sail, \& Xavier, 2012). Out-of-pocket payments for LTC services, for which very little or no reimbursement is offered, correspond to a growing share of individual income (90\% to $130 \%$ in France in 2008 , for instance (Ernst \& Young, 2008)). Increased demand for LTC is expected, owing to the extended longevity and the incidence of dependency (European Commission, 2008). As a result, total public spending on LTC is anticipated to be as high as 3.6\% of European GDP in 2060 (Lipszyc et al., 2012).

One of the answers to the need for controlling nursing homes' costs lies in mergers and acquisitions (M\&A). A significant body of academic research provides arguments that support the concept of economies of scale. Large nursing homes are said to centralize administration and management, to lower labor costs, owing to the sharing of administrative staff, as well as to have superior business models, higher purchasing power, higher utilization rates, and marketing benefits (Anderson, Lewis, \& Webb, 1999; Lu \& Wedig, 2013; Smith \& Fottler, 1981). There are also costs to M\&A activity. Examples include inefficiency arising from bureaucratic constraints and coordination problems (Anderson et al., 1999). This article examines whether there are differences in efficiency between chain-affiliated nursing homes and those managed by independent owners. Specifically, we test chain size's influence on cost efficiency.

We further analyze whether and how nursing homes' cost efficiency is modified when external actors exert pressure. We rely on the framework developed by Cardinaels and 
Soderstrom (2013). They identify three types of external forces in the institutional environment of hospitals: governmental bodies, ownership structure, and health care market. This illustrates the complexity and richness of the institutional environment in which health care providers operate. We transpose this framework to nursing homes and assess the impacts of some institutional stakeholders' actions. In particular, we predict that cost efficiency increases with pressures from local governments, shareholders, and the nursing home market.

The motivation for this study is threefold. First, more in-depth investigations of the European LTC sector organization are needed. Lucrative nursing homes have recently entered the LTC sector in Europe. Although they are still in minority (for-profit firms operate only $20 \%$ of available beds in France (Direction de la Recherche, des Études, de l'Évaluation et des Statistiques ${ }^{1}$ [DREES], 2014)), they are developing rapidly. ${ }^{2}$ Given their relative youth, forprofit nursing facilities have received only limited attention from academics to date. European studies on the LTC sector mainly focus on the non-profit sector (Dewaelheyns, Eeckloo, Van Herck, Van Hulle, \& Vleugels, 2009; Farsi \& Filippini, 2004). Anglo-Saxon countries exhibit a different pattern, with a majority of nursing homes being operated by for-profit institutions. ${ }^{3}$ Several studies have focused on the for-profit sector in these countries. Unfortunately, their findings may not be transposed in the European setting, given the differences between the institutional environments. The latter differs, in particular, in price regulation ${ }^{4}$ and the nature of competition, since the European market is dominated by non-profit.

Second, a recent call by practitioners for additional work notes that ' $[\ldots]$ the available studies did not allow comparison of the possible impact of factors such as subcategory of forprofit ownership (for example, chain versus non-chain) [...]' (Comondore et al., 2009, p. 15).

\footnotetext{
${ }^{1}$ Department for Research, Studies, Assessment, and Statistics.

${ }^{2}$ For-profit organizations own almost one-third of beds created between 2007 and 2011 (DREES, 2014).

${ }^{3}$ For-profit ownership accounts for $50 \%$ of nursing homes in Canada (Comondore et al., 2009), 67\% in the U.S. (Grabowski, Feng, Hirth, Rahman, \& Mor, 2013) and 76.8\% in the UK (Forder \& Allan, 2011).

${ }^{4}$ See Sections 2.2. and 3.2. for more details.
} 
Previous research has mainly used a profit-based distinction (intercategory). Empirical findings are convergent and robust: non-profit nursing homes operate less efficiently than their for-profit counterparts (Aaronson, Zinn, \& Rosko, 1994; Knox, Blankmeyer, \& Stutzman, 2007). In that case, nursing homes face different incentives. Non-profit organizations do not have welldefined objective functions (Eldenburg \& Krishnan, 2003), and their underlying goals may vary significantly (Dewaelheyns et al., 2009; Eldenburg, Hermalin, Weisbach, \& Wosinska, 2004). Thus, non-profit nursing homes maximize quality or size or have altruistic objectives, which generates inefficiency ${ }^{5}$ (McKay, 1991; Newhouse, 1970). By contrast, for-profits tend to maximize profits. Our study differs from most of the previous ones in that we only consider for-profit ownership (intra-category) and define subcategories based on chain affiliation. Potential distinct cost patterns within the for-profit category have not come under deep scrutiny. Thus, we focus on both independent and chain-affiliated for-profit nursing homes, since any difference between efficiency levels appears less obvious.

Third, the LTC sector requires specific empirical designs. Some studies based on U.S. data compare efficiency between independent and chain-affiliated nursing homes using nonparametric estimation methods (data envelopment analysis (DEA) methods) (Anderson, Weeks, Hobbs, \& Webb, 2003; Fizel \& Nunnikoven, 1993). Nursing homes are constrained by residents' heterogeneity and differences in quality, among others. Careful consideration of these exogenous cost factors is essential if one is to obtain non-biased efficiency analysis. DEA methods may not duly consider some of these characteristics, particularly when exogenous variables are not continuous (Coelli, Rao, O’Donnell, \& Battese, 2005). We depart from this approach by relying on a parametric method, which enables the inclusion of several cost factors. Indeed, Coelli, Estache, Perelman, and Trujillo (2003) state that this approach is more amenable to modeling the effects of environmental variables than DEA.

\footnotetext{
${ }^{5}$ Some studies investigate differences in performance across the non-profit category (see Dewaelheyns et al., 2009,
} or Eldenburg \& Krishnan, 2003, for instance). 
We tested our predictions on a cross-sectional sample of 370 for-profit French nursing homes. We divided the sample into three groups, based on the number of facilities in the chain: zero, medium, and large. We adopted a methodology based on a frontier method. We computed inefficiency scores corresponding to the nursing homes' distance to the best practice industry cost frontier. Our cost frontier was estimated by stochastic frontier analysis (SFA). We included in our model a large set of variables measured at the facility level. We incorporated observable features such as geographic position, qualification-adjusted staff compensation, and patient dependence. Fundamental to our study, we introduced quality of care in three complementary ways: staffing intensity, staff skills, and lodging comfort.

Our key results provide evidence of a significant increase in cost inefficiency with chain size. In particular, we demonstrate that cost inefficiency represents $10.6 \%$ for the medium-sized group. This means that costs could be reduced by $10.6 \%$ on average. Cost inefficiency is even higher for the large group (21.1\%). This relationship is robust to alternative specifications such as quantile regressions, inclusion of a continuous variable for chain size, and another definition of costs. Overall, our results suggest that chains are unable to achieve expected cost efficiency gains. Next, we supplement this major result by documenting significant influences on cost efficiency from the institutional environment of nursing homes. External pressures from local governments and shareholders are positively and significantly associated with the realization of cost containment.

Our results add to the prior literature in several ways. First, this study can help policymakers to set reimbursement methods. They need accurate cost analysis to '[...] set reimbursement rates according to ownership type in their effort to control costs [...]' (McKay, 1991, p. 122). We take a step in this direction by documenting a negative influence of chain affiliation on cost efficiency in the French context. Our empirical evidence also provides valuable insights for policy-makers, nursing home administrators, and academics in Europe 
who are considering current and future ownership structures in the LTC sector (Cardinaels, 2009).

Second, we offer an additional institutional perspective in assessing chain affiliation's impact on performance. Holzhacker, Krishnan, and Malhendorf (2015) observe that hospital cost structures are highly dependent on institutional pressures and recommend investigating the effects of institutional constraints to avoid obtaining misleading or inconclusive results. Hence, we show that, similarly to hospitals, many external stakeholders exert pressure on nursing homes and influence how resources are managed (Cardinaels \& Soderstrom, 2013). Responses to pressures from their environment allow nursing homes to reach higher performance levels. To attain affordable and high-quality LTC, the European Commission (2008) recommends optimal use of resources, and thus the implementation of appropriate incentives for providers. Our identification of external forces associated with cost mitigation aids future policy orientation.

Third, we contribute to the growing body of research on alternative measures of performance. In the health care sector, performance is a broad concept that can be measured in a number of ways (Cardinaels \& Soderstrom, 2013; Van Peursem, Pratt, \& Lawrence, 1995). We go beyond the traditional use of financial and accounting indicators by adopting a frontier method. Inefficiency scores allow for a more comprehensive and accurate understanding of nursing home performance (Chen, Delmas, \& Lieberman, 2015; Margaritis \& Psillaki, 2007; Shyu, 2013).

Finally, this study introduces a large set of variables to capture quality of care. Empirical research on nursing home costs must include quality aspects but, as Di Giorgio, Filippini, and Masiero (2014, p. 2) note, previous research '[...] marginally addresses quality of care'. We include four variables to proxy for quality of care. Most importantly, one of them is a selfconstructed index measuring lodging comfort aggregating a wide range of features (e.g. green 
area, accessibility, equipment in rooms). These methodological improvements are fundamental, so that (often costly) quality is not associated with inefficiency.

The remainder of this paper is organized as follows. In Section 2, we offer an overview of the French nursing home institutional environment. In Section 3, we review the relevant literature and specify our four hypotheses. In Section 4, we describe the data, the model, and the variables used in the estimation. In Section 5, we describe regression results and robustness checks. In the final section, we derive implications and conclude.

\section{Institutional Background}

\subsection{For-Profit Sector and Concentration}

The French LTC industry is structured as a network of (private and public) non-profit ( $80 \%$ of beds in 2011 (DREES, 2014)) and for-profit (20\% of beds in 2011 (DREES, 2014)) nursing homes. Chain operators have rapidly gained prominence in the for-profit category. More than two-thirds of for-profit beds were part of chains in $2011 .{ }^{6}$ In particular, the three largest groups (Korian-Medica, Orpea, and DVD) now account for $45 \%$ of beds, compared to $33 \%$ in 2007.7 The market share held by chain nursing homes in the for-profit category continues to grow and provides evidence of its increasing presence as an organizational form in the LTC sector (Ingram \& Baum, 1997).

This trend generates substantial hope for lower costs, which justifies the current political will to promote concentration. First, openings of new facilities are highly regulated. Any prospective operator must answer a call for bids issued by local authorities (Agences Régionales de Santé), which oversee licensing. The current legislation favors large groups, since they benefit from higher financial credibility. They also maintain effective relationships with local

\footnotetext{
${ }^{6}$ Source: own computation from Ernst \& Young (2008) and 2011 EHPA (Établissement Hébergeant des Personnes Âgées) survey (DREES).

${ }^{7}$ Source: own computation from Ernst \& Young (2008) and 2011 EHPA survey (DREES).
} 
authorities. ${ }^{8}$ Second, recent regulations have raised the standards governing safety and wellbeing. For instance, facilities are required to have an air-conditioned room (decree no 2005768, dated 7 July 2005) and wheelchair access to all rooms (law accessibilité no 2015-988, dated 5 August 2015). Meeting stringent standards proves to be difficult for many small independent nursing homes, in financial and administrative terms. As a result, larger (multihome) chains are able to acquire weakened smaller facilities.

The scope of this ongoing consolidation movement is not limited to France. French chain operators are expanding their activities in other European countries. For instance, KorianMedica - the largest group in France in terms of market share- owns several subsidiaries in the European Union, including Segesta (second largest private group in Italy) and Phönix (eighth largest private group in Germany) (Korian, 2011). Orpea - the second largest group in France in terms of market share-claims to be the European leader in dependency care. The group emphasizes an 'acceleration of development outside France' (Orpea, 2014), as evidenced by its recent acquisitions. ${ }^{9}$ Its European network now spans France $(31,871$ beds in 345 facilities $(62 \%$ of total $))$ and other adjacent countries such as Belgium, Germany, Italy, Spain, and Switzerland (19,388 beds in 176 facilities (38\% of total)). As a result, conclusions derived from this paper are likely to inform interested parties in other European countries.

\section{2. $\quad$ Price and Quality}

The current flourishing concentration movement faces the twofold challenge of price and quality. First, nursing home prices are high and are increasing sharply in France, especially in the private for-profit sector (Ernst \& Young, 2008). Given the mix between public and private financing sources, this increase in prices is borne by national solidarity and residents (out-of-

\footnotetext{
${ }^{8}$ Relationships with local authorities are considered to be strategic. Several large groups possess internal services entirely dedicated to these activities.

${ }^{9}$ In 2012, Orpea acquired Artevida in Spain and, in 2014, Senevita in Switzerland and Silver Care in Germany.
} 
pocket payments). Daily prices are partially regulated via the delineation of three main activities:

(1) medical: this price encompasses health expenditures (e.g. medical equipment, physicians' wages, and nurses' wages);

(2) nursing care: this price encompasses dependency expenditures (e.g. part of nursing auxiliaries' wages);

(3) lodging: this price encompasses residual costs (e.g. entertainment, technical and administrative staff, various purchases, and food). It accounts for up to $70 \%$ of the total price. ${ }^{10}$

Local authorities regulate medical prices, as well as nursing care prices. The latter are set according to actual costs of nursing homes (cost-based payment scheme): the more costly nursing homes are, the higher prices they charge. This system does not provide any incentives for cost containment. But local governments may exert pressure on prices to incite nursing homes to better control their costs.

Contrary to the medical and nursing care prices, the lodging price is freely set by most for-profit nursing homes. ${ }^{11}$ Nursing homes thus have strong incentives to lower lodging costs, in order to maximize profits. Cost efficiency may also come from competition. Since residents are price-sensitive, price competition develops in areas where the number of facilities is large (Martin, 2014). This increases the incentive to contain costs.

At the same time, increased cost efficiency should not be detrimental to quality of care, which is reported to be low in France. Notably, resident-to-staff ratios are below average: 5.7 per 10 residents in France (Ratte \& Imbaud, 2011), compared to 12 per 10 residents in Germany, for instance (Létard, Flandre, \& Lepeltier, 2004), which strongly affects residents' well-being

\footnotetext{
${ }^{10}$ Source: own computation from 2011 EHPA survey (DREES).

${ }^{11}$ Some facilities are entirely regulated: their lodging price is also set according to a cost-based payment mechanism. Several non-profit nursing homes are in this situation. Conversely, only very few for-profit nursing homes are totally regulated. To ensure relevant comparisons across for-profit nursing homes, we omitted entirely regulated nursing homes from our final sample.
} 
(Dormont \& Martin, 2012). Staffing ratios are even lower in the for-profit sector. In 2011, the average number of nurses equals 0.45 per 10 residents in for-profits, 0.48 per 10 residents in private non-profits, and 0.50 per 10 residents in state-controlled non-profits in France (Ratte \& Imbaud, 2011). The same pattern is observed regarding nursing auxiliaries: 1.4 for 10 residents in for-profits, 1.50 for 10 residents in private non-profits, and 1.85 per 10 residents in statecontrolled non-profits (Ratte \& Imbaud, 2011). It is thus fundamental to include quality of care in the analysis of for-profit nursing homes, so as to control for its effect on costs. Our empirical design section describes several proxies for quality of care.

\section{Prior Literature and Hypotheses Development}

We develop two sets of hypotheses. The first set examines the relationship between chain size (i.e. the number of nursing homes operated by a chain) and cost efficiency of for-profit nursing homes. The second set of hypotheses examines how diverse political and economic pressures from the institutional environment influence cost efficiency.

\subsection{Chain Affiliation and Cost Efficiency}

Although LTC cost containment is an issue of continuing concern, it remains difficult to assess the impact of chain ownership in this regard.

Large chains are alleged to reduce costs through realization of firm-level economies of scale. Firm-level economies of scale are computed from the number of nursing homes in the group. The objective is to determine whether chain-affiliated nursing homes bear lower average costs than independent ones for any given output level. Firm-level economies of scale differ from plant-level economies of scale, which are computed from nursing home size. Although they are very different, both are assessed on a facility-by-facility basis.

Higher cost efficiency of facilities in chains may derive from several fields. First, from an operational perspective, chain-affiliated nursing homes centralize and standardize administrative services such as accounting for financial reporting purposes as well as operating 
processes. They can also balance out any temporary bed disequilibrium (surplus or shortage) by transferring residents among nursing homes affiliated to the same chain in some cases. As a result, they are less affected by capacity constraints (Anderson et al., 2003). Greater bargaining power and volume discounts arising from joint purchasing are also anticipated (Ernst \& Young, 2008). Second, human resources management effectiveness can improve. Similarly to hospitals, chain-affiliated nursing homes might have more motivated workers attracted by career advancement opportunities and more elaborate compensation packages (Menke, 1997). A positive learning dynamic is also expected, since chains can rapidly transmit information gathered from one facility to another (Anderson et al., 2003). Professional managers are more easily hired by large chains, which facilitates knowledge transfer and change implementation (Banaszak-Holl, Berta, Baum, \& Mitchell, 2002). Third, general marketing campaigns might generate positive spillover effects, since they enhance current and potential residents' ability to recognize the chain name. Making the chain name more recognizable will then result in subsequent lower spending on advertising (Lafontaine \& Slade, 2007).

Claims by LTC actors accord with theoretical predictions. Jean-Claude Marian, the board chairman of Orpea, estimates that 'thanks to cross-company functions, [chains] can contain costs'. ${ }^{12}$ In its 2013 annual report, Korian considers that 'pooling expertise and sharing good practices should benefit operational performance [...]' (p. 4). In a recent report, audit firm Ernst \& Young (2008) considers that 'synergies among operators arising from concentration can generate operational improvements' (p. 19). Overall, this suggests that nursing home chains are more capable of cost savings than independently owned nursing homes.

Conversely, chain organization may incur extra costs related to some diseconomies of scale. An increased number of facilities makes decision-making processes slower and more complex (Anderson et al., 2003), which can prevent chain nursing homes from rapidly adapting

\footnotetext{
${ }^{12}$ Source: Les Échos, 278, April 2011.
} 
to local specificities. The high routinization sometimes observed in chains raises concerns that they fail to introduce necessary changes in both strategy and practices of their local nursing homes (Banaszak-Holl et al., 2002). Management teams face greater coordination difficulties and may find it difficult to manage geographically dispersed facilities (Banaszak-Holl et al., 2002). As is evidenced in headquarters' hypertrophy (Ernst \& Young, 2008), chains develop impersonal and bureaucratic contexts that may lead to resource wastage (Anderson et al., 1999). Overall, this suggests that chain organization imposes additional costs, compared to independently owned nursing homes.

Based on the arguments previously mentioned, the effects of chain organization on cost efficiency are unclear. Both affiliation (belonging to a chain vs. being independent) as well as the size of the chain (medium vs. large) will be investigated to study the impact of nursing home chain size, leading to our first hypothesis, stated in the null form:

Hypothesis 1 (H1): There is no relationship between nursing home chain size and cost efficiency.

\subsection{Institutional Pressures}

\subsubsection{Relevance of the Institutional Environment}

Before describing our next three hypotheses, we will discuss why several institutional features of the nursing home industry may affect performance. A large number of actors are present in the LTC environment, and nursing homes evolve within a broad institutional context (Gibson \& Barsade, 2003). Similarly to hospitals, some external actors can exert pressure on nursing homes, so as to positively impact their resources management (Cardinaels \& Soderstrom, 2013). According to Carmona and Macias (2001, p. 143), pressures '[...] concern conformity to social norms of acceptable behavior as well as demands to accomplish satisfactory levels of performance (Covaleski, Dirsmith, \& Samuel, 1996, p. 11)'. Since cost containment is one dimension of performance, pressures emanate from some external stakeholders to improve cost 
efficiency. Stakeholder's power corresponds to its influence over the resources needed by the entity (Roberts, 1998). Nursing homes are heavily dependent on the external environment to get resources (Smith \& Fottler, 1981), which gives some stakeholders great power over them. To convey a relevant picture and access resources, nursing homes are encouraged to respond to public pressures. We predict that this dynamic will enhance cost efficiency levels investigated in Hypothesis 1.

We rely on the framework developed by Cardinaels and Soderstrom (2013) to study institutional pressures exerted on nursing homes and test these pressures' effects. Three external forces characterize nursing homes' institutional environment: governmental bodies, the ownership structure, and the health care market. We envision that these three levels influence for-profit nursing home cost efficiency.

\subsubsection{Governmental Bodies}

External constituents, such as governmental bodies, especially matter when organizations are highly dependent on the resources they supply (Abernethy \& Chua, 1996; Brignall \& Modell, 2000). To remain legitimate and to avoid resource scarcity, organizations must actively respond to institutional pressures. This induces organizational conformity to institutionalized beliefs promulgated by corporate agencies (Abernethy \& Chua, 1996). This commonly observed behavior is transferable to nursing homes operating in a highly institutionalized environment, such as in France, where a great number of corporate agencies are present at the local level and determine the way for-profit nursing homes operate.

The main French governmental body operating at the local level is the Conseil Général. ${ }^{13}$ The Conseils Généraux are in charge of most of the decisions regarding nursing homes. They have a high capacity to affect costs through their bargaining power which is exercised in two main directions. First, the Conseils Généraux use a cost-based payment

\footnotetext{
${ }^{13} \mathrm{~A}$ Conseil Général operates at the county (département) level. The French metropolitan territory is divided into 96 départements.
} 
mechanism to set nursing care prices (see Section 2.2. for a reminder) and directly take charge of them. As a result, they tend to exert pressure on nursing homes to contain nursing care costs. The scope of intervention of public authorities is far broader in France than in other institutional contexts such as the much-studied U.S. context. In U.S. skilled nursing homes and intermediate care facilities, only prices for Medicaid or Medicare patients are regulated and subsidized. This is not the case in France, where the Conseils Généraux set nursing care prices for all patient types and for all nursing homes. Second, since some residents cannot afford to pay the lodging price, the Conseils Généraux grant them allocations (the Health Area Social Allowance) as a result of public solidarity, which burdens their budget. This leads the Conseils Généraux to exert pressure on nursing homes to contain lodging costs.

In particular, we predict that public authorities in France (Conseil Général at the county level) put different pressures on nursing homes. First, there is a large variation in financial resources reserved for elderly care between counties (départements). Second, there is a variation in political pressures on for-profit nursing homes due to the political orientation of the Conseil Général in office. The answer to these different kinds of pressures should lead nursing homes to become more cost-efficient. Following this reasoning, we hypothesize:

Hypothesis 2 (H2): Pressure from local government increases nursing home cost efficiency.

\subsubsection{Ownership Structure}

Shareholders of for-profit nursing homes differ concerning at least one major dimension: their listing status. An increasing number of nursing home chains launch themselves on the stock market to benefit from growth opportunities and to gain easier access to funding. ${ }^{14}$ Differences in ownership result in different incentives for managers, which may influence the efficiency level they reach (Chang, Chang, Das, \& Li, 2004; Eldenburg et al., 2004). Nursing homes with

\footnotetext{
${ }^{14}$ For instance, Orpea has been listed on Euronext Paris since April 2002, Le Noble Age since June 2006, Korian since November 2006, and Medica since February 2010 (Korian and Medica merged in March 2014).
} 
unlisted shares and no access to equity capital markets differ from listed groups, since they pay minimal attention to current shareholder value. Nursing homes whose shares are publicly traded are supposed to be more responsive to shareholder claims and to be affected by market discipline mechanisms in a number of ways. Ex ante, initial profit margins must be high (relative to other firms in the industry), in order to attract investors, who are becoming increasingly demanding concerning expected profitability. To be able to meet shareholder expectations of value, Holzhacker et al. (2015) point out that for-profit nursing homes adjust their costs on a regular basis. The audit firm Ernst \& Young (2008) highlights the trade-off nursing homes face: prices must be low, so as to be accepted by residents, as well as high enough to allow operators to quantitatively and qualitatively develop their business. Ex post, there is a need for monitoring, since listed nursing homes are more likely to incur agency problems (e.g. management's shirking, perk consumption). The discipline of equity markets may offset agency costs and may limit managerial discretion. Among others, monitoring is directed towards stock price maximization ${ }^{15}$ and, in turn, cost efficiency. Following this reasoning, we hypothesize:

Hypothesis 3 (H3): Pressure from shareholders increases nursing home cost efficiency.

\subsubsection{Health Care Market}

Market forces play an important role in LTC cost containment (Cardinaels \& Soderstrom, 2013). For instance, cost reduction strategies and operational efficiency improvement in U.S. hospitals depend on market position (Hsu \& Qu, 2012). Competitive pressures compel managers to maintain low costs, in order to survive (Ewing, Kruse, \& Thompson, 2005). This is especially true if price competition prevails. In that case, Krishnan (2005) documents an increased demand for accounting information (proxied by expenditures on accounting), which

\footnotetext{
${ }^{15}$ Top managers receive stock options and other remunerations linked to the share price in compensation packages.
} 
may make cost control easier. Conversely, high market power reduces incentives for local facilities to operate efficiently (Banaszak-Holl et al., 2002).

In France, several chain facilities can be found in one neighborhood. Some nursing home chains sometimes even deliberately seek such close locations. Korian claims a cluster strategy: it builds or acquires new facilities in a geographically restricted area. In this situation, new openings increase the power of geographically concentrated chains. If management of resources is influenced by the nursing home market's competitiveness, increased bargaining position and market shares may result in lower incentives to reduce costs. Taken together, these arguments lead us to hypothesize:

Hypothesis 4 (H4): Nursing home market pressure increases nursing home cost efficiency.

\section{Empirical Design}

\subsection{Research Sample}

Our sample, which we draw from a proprietary database provided by the DREES of the French Ministry of Social Affairs, consists of French nursing homes. DREES conducts a comprehensive survey of all French nursing homes every four years; we used the most recent one (2011 EHPA survey). We supplemented it with data from several other databases. We collected cost information from the DIANE database, which contains the 2011 financial statements. We also obtained 2010 administrative data on wages from the Institut National de la Statistique et des Études Économiques ${ }^{16}$ (INSEE).

Our focus is on independent and chain-affiliated for-profit nursing homes. They account for about $20 \%$ of the total number of beds in France in 2011 (DREES, 2014). We did not include non-profit nursing homes, for two reasons. First, this sector does not exhibit the same trend towards concentration as for-profits (see Section 2.1.). Second, non-profit nursing homes do

\footnotetext{
${ }^{16}$ French National Institute for Statistics and Economic Studies.
} 
not have the same incentives for profit maximization, and pursue different objectives (Newhouse, 1970). We omitted for-profit nursing homes whose prices are totally regulated by the French State (see Section 2.2.). In addition, we excluded from the initial for-profit sample all nursing homes for which we did not have information on variables included in the model. Our final sample consists of 370 for-profit nursing homes in 2011. We assessed firm-level economies of scale on a facility-by-facility basis by considering each nursing home as a separate unit of analysis.

\subsection{Cost Model}

In this section, we define the cost model that we estimate with a parametric estimation method (see Section 4.3. for the estimation). We assumed that nursing homes produce resident-days (ResidentDays) (output), using several staff categories $i$ as inputs. We assumed wages per staff category $\left(\right.$ Wages $\left._{i}\right)$ to be set on a competitive basis in their respective markets. We also included several variables $\left(z=\sum_{k} z_{k}\right)$ that generate specific costs, related to residents' characteristics and nursing home quality. We explain total costs (COSTS) by the following cost function: COSTS $=f($ ResidentDays, Wages $i, z)$.

We selected a simple functional form of the cost function, following Christensen's approach (2004):

$$
\operatorname{lnCOSTS}=\alpha_{0}+\alpha_{R D} \text { ResidentDays }+\alpha_{R D^{2}} \text { ResidentDays }^{2}+\sum_{i} \alpha_{w_{i}} \ln \left(\text { Wages }_{i}\right)+\sum_{k} \alpha_{z_{k}} z_{k}(1)
$$

\subsection{Estimation Method}

To analyze cost efficiency, we used a SFA of the cost model. First, this method estimated a cost frontier that would correspond to the cost function (as defined in Section 4.2.) of a fully efficient nursing home. Second, we assessed the distance of each nursing home to this frontier. We treated the difference as cost inefficiency. Third, we determined whether chain affiliation and institutional pressures from external actors explain the estimated cost inefficiency. 
Methods other than SFA may be used to estimate a cost frontier. Some authors use nonparametric methods such as DEA (Anderson et al., 2003; Fizel \& Nunnikhoven, 1993). They mostly include no, or only a few, environmental variables in their linear program. Inefficiency scores are first derived using DEA and then regressed on environmental variables using an ordinary least squares (OLS) regression. This multistage approach amounts to assimilating environmental variables to inefficiency factors, and not to cost factors. With this approach, it is difficult to precisely measure inefficiency scores. To overcome this, more complex DEA onestage estimations can be used (Banker \& Morey, 1986), as well as parametric methods such as SFA. SFA estimations seem relevant concerning the nursing home industry (Anderson et al., 1999), because they allow for an easy inclusion into the cost model of a large number of exogenous cost specificities (e.g. geographical location, resident case mix, and quality of care). If we do not duly take them into account, the construction of the cost frontier and inefficiency assessment will be biased. Thus, we estimated a cost model including a large number of control variables $z_{k}$ (defined in Section 4.4.). Despite this, SFA has some disadvantages. It makes strong assumptions concerning the inefficiency term distribution (see below) (Coelli et al., 2005).

SFA is based on a breakdown of the error term into two components. The first corresponds to nursing home $e$ inefficiency $\left(u_{e}\right)$, and the second to statistical noise $\left(v_{e}\right)$. Different parametric assumptions on $u_{e}$ and $v_{e}$ distributions allow identification of these two components. $u_{e}$ is an asymmetric term only increasing costs, while $v_{e}$ has either a positive or a negative impact on costs. The cost function is estimated with a maximum likelihood estimation method, as suggested by Aigner, Knox Lovell, \& Schmidt (1977) and Meeusen \& van den Broeck (1977).

$$
\ln \operatorname{COSTS}_{e}=\ln \operatorname{COSTS}\left(X_{e}\right)+u_{e}+v_{e}
$$

with $\ln \operatorname{COSTS}_{e}$ as the logarithm of actual costs of the facility $e, \ln \widehat{\operatorname{OSTS}}\left(X_{e}\right)$ the logarithm of predicted costs, $X_{e}$ the vector of explanatory variables for nursing home $e$, and $u_{e} \geq 0$. 
Then,

$$
\begin{gathered}
\operatorname{COSTS}_{e}=\operatorname{COSTS}\left(X_{e}\right) * \exp \left(v_{e}\right) * \exp \left(u_{e}\right) \\
\text { and } \\
C I_{e}=\frac{\operatorname{COSTS}_{e}}{\operatorname{COSTS}\left(X_{e}\right) * \exp \left(v_{e}\right)}=\exp \left(u_{e}\right) \geq 1
\end{gathered}
$$

with $C I_{e}$ as the cost inefficiency score for nursing home $e$.

The inefficiency score is the ratio of the nursing home's actual costs to the costs the nursing home could have achieved if it were fully efficient. If nursing home $e$ is fully efficient, then $u_{e}=0$ and $C I_{e}=1 .{ }^{17} \mathrm{~A}$ nursing home is all the more inefficient if $C I_{e}$ is far from 1.

The SFA method requires strong assumptions about the functional form of the cost model and the distribution of the efficiency term. The shape of the likelihood function, and therefore estimated results, depends on the distribution of $u_{e}$ (Newhouse, 1994). We chose a normal-truncated normal distribution of the disturbance, with $v_{e} \sim \operatorname{iidN}\left(0, \sigma_{v}^{2}\right), u_{e} \sim \operatorname{iid} N^{+}\left(\mu, \sigma_{u}^{2}\right)$, and $\mu=\delta m_{e}+\eta_{e}\left(m\right.$ : explanatory environmental variables of inefficiency, ${ }^{18}$ and $\eta$ : statistical noise). As performed by Battese and Coelli (1995), we used a one-step approach in which $u_{e}$ is directly replaced in the cost function by its explanatory variables. ${ }^{19}$

\subsection{Definitions of Variables}

\subsubsection{Dependent Variable}

In our cost model, the dependent variable (COSTS) proxies for costs of nursing homes. We used the logarithm of total annual operating expenses in thousands of euros $(€)$. The main items

\footnotetext{
${ }^{17} u_{e}$ and $C I_{e}$ are estimated using the formulation suggested by Jondrow, Knox Lovell, Masterov, and Schmidt (1982).

${ }^{18}$ Explanatory environmental variables of inefficiency are, depending on the regressions, either the chain size or variables in the institutional environment.

${ }^{19}$ This approach is better than a two-step one where the following steps are successively performed. First, a stochastic cost frontier is estimated, assuming that inefficiency scores are independently and identically distributed. Second, inefficiency scores are regressed on a collection of explanatory variables. The second step is just to contradict the assumption of independent inefficiency terms, which could lead to inefficient estimates (Battese \& Coelli, 1995) or biased estimates of inefficiency scores (Wang \& Schmidt, 2002).
} 
included in the operating expenses were purchases, changes in inventories, salaries and wages, rent expenses, depreciation and amortization expenses, and other operating expenses.

\subsubsection{Explanatory Variables of the Cost Frontier}

Modeling a cost function requires integrating output and input prices. As in most of studies on nursing homes' cost efficiency (Christensen, 2004; Farsi \& Filippini, 2004; Knox, Blankmeyer, \& Stutzman, 2001; Vitaliano \& Toren, 1994), output corresponds to the annual number of resident-days (ResidentDays) produced. Input prices are the logarithm of average annual gross wages of staff depending on their skills $i$. To refine our analysis, we define three main staff categories following Vitaliano and Toren's approach (1994): nurses (WagesN), nursing

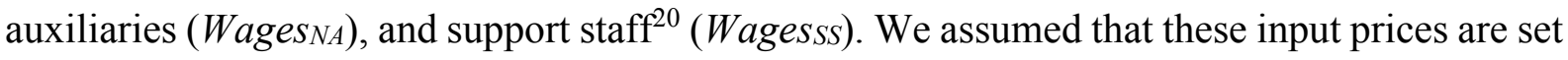
exogenously, i.e. that nursing homes are price takers in a competitive labor market. If this hypothesis is valid, we predict that wage variables will have a positive and significant effect on costs. $^{21}$

We also added variables to control for some residents' characteristics (Farsi \& Filippini, 2004). We measured dependence of the elderly along a French national scale, which allows for the classification of aged people into six resource utilization groups (RUG), depending on their dependence level. The most dependent people are classified in RUG 1, then RUG 2, to the least dependent in RUG 6. We included the proportions of residents in each RUG group in our cost model, with six variables named $\% R U G 1$ to $\% R U G 6$.

We also included three variables related to property costs to better estimate the real frontier of nursing homes. First, BuildOwn is a categorical variable that provides information on building ownership. It is coded 1 when the nursing home owns its buildings, 0 otherwise. Second, Urb is the urbanization level of the town or city in which the nursing home is located;

\footnotetext{
${ }^{20}$ Support staff members are low-skilled and provide no care services.

${ }^{21}$ When they are present, wages of high-skilled managers (e.g. physicians) represent a substantial part of staff costs. However, under certain conditions, their use of accounting information systems for cost control, and thus their increased cost consciousness, may lower costs (Abernethy \& Vagnoni, 2004).
} 
it is computed depending on the number of inhabitants. Third, Attract represents the attractiveness of the town or city to tourists; it is defined as the ratio of the number of secondary (holiday) homes to the total number of houses.

Finally, we included various nursing home characteristics related to the French context that may influence costs. Some for-profit facilities admit residents who are fully covered by public funds. ${ }^{22}$ Lodging fees are set by public authorities for these residents. Thus, there are two lodging prices in these partially regulated nursing homes: one for private residents and another one for subsidized residents. We included a binary variable (PartiallyRegulated) equal to 1 when the nursing home admits some subsidized residents, 0 otherwise. We also controlled for facility age (ActivityLength), i.e. the number of years since it opened. We expect this variable to impact on costs, for various reasons. On the one hand, it likely correlates with building age and equipment age. New buildings and equipment may increase costs, since nursing homes must bear depreciation expenses. ${ }^{23}$ On the other hand, nursing home aging provides an opportunity for learning by doing effects for administrative and nursing staff, which may induce cost savings. Drugstore is coded 1 if the nursing home has its own drugstore, 0 otherwise. Finally, we controlled for the medical care price system for which the nursing home opts (partial or global). ${ }^{24}$ PriceOption is coded 1 if the nursing home has chosen the global option, and 0 if it has chosen the partial option.

\subsubsection{Quality as Explanatory Variables}

The integration of quality variables in a cost model is fundamental, in order to assess inefficiency via a frontier estimation method. However, many authors do not include quality variables when studying nursing home efficiency. The often costly unobserved quality is then

\footnotetext{
${ }^{22}$ These residents benefit from the Health Area Social Allowance (see Section 3.2.).

${ }^{23}$ To isolate the effect of building aging and equipment aging, we conducted a robustness check where ActivityLength is replaced by BuildAge (see Section 5.4.).

${ }^{24}$ With the global option, the reimbursed health benefit basket is large, because it includes GPs' fees, radiography, and biological analyses. With the partial option, residents first pay for these medical care services and are then reimbursed by their own health insurance.
} 
treated as inefficiency: 'nursing homes that offer higher quality services may appear to be cost inefficient' (Anderson et al., 2003, p. 45). Harrington, Woolhandler, Mullan, Carillo, and Himmelstein (2001) note that U.S. chain-affiliated nursing homes have lower quality levels than their independent counterparts. Without any control for these features, one may conclude that chain-affiliated nursing homes are more cost-efficient.

To overcome this issue, some authors use health status variables as quality of care controls. For instance, Weech-Maldonado (2006) uses pressure ulcers worsening and mood decline. We do not possess this type of variable for the nursing homes included in our sample. Consequently, we used other variables which are a reasonable proxy ${ }^{25}$ for nursing home quality.

First, as done by Dormont and Martin (2012), we used a staff ratio. Staff ratio (Staff), which accounts for differences in resident needs, is defined as the current number of persons hired by the nursing home $(N)$ divided by the theoretical number of staff members needed $\left(N^{*}\right)$. $N$ includes all non-administrative or technical staff. ${ }^{26}$ With this procedure, any savings related to caregivers and entertainment staff, made possible by chain affiliation, do not appear. However, these synergies seem limited, unlike those that may exist for technical and administrative staff. $N^{*}$ is the quantity of full-time equivalent staff members needed per day for an elderly person, depending on his or her RUG group. ${ }^{27}$

Second, staff members' skills levels also affect quality of care (Cohen \& Spector, 1996). Some nursing homes substitute registered nurses with nursing auxiliaries or even with support staff. Detrimental effects to the residents' well-being, such as absence of treatment of bedsores or iatrogenic disorders, may arise (Réjault, 2011). We integrated into the cost model the ratio

\footnotetext{
${ }^{25}$ Using another sample of facilities in France, Dormont and Martin (2012) show that they are significantly correlated with residents' health status.

${ }^{26} \mathrm{We}$ do not include replacement staff, so as not to assimilate high quality and high absenteeism level.

${ }^{27}$ The corresponding needs are established for the formal home care sector. The quantity of full-time equivalent staff members needed per day is equal to 1 for a RUG 1 person, 0.84 for a RUG 2 person, 0.66 for a RUG 3 person, 0.42 for a RUG 4 person, 0.25 for a RUG 5 person, and 0.07 for a RUG 6 person (Ratte \& Imbaud, 2011).
} 
of highly skilled employees (physicians and nurses) to total staff (\%HighSkill). Similarly, the ratio of nursing assistants to total $\operatorname{staff}^{28}(\%$ MediumSkill) was added.

Third, we also added a variable related to residents' accommodation comfort (Comfort). The accommodation comfort variable ranges from 0 to 120 . We assigned points to various features: environment quality, building quality, the quality of the living and care areas, room comfort, equipment in rooms, green area, and accessibility. We developed this indicator from the methodology used in a French comparative survey. We attributed a score to each facility, based on a comprehensive coding grid presented in Table 1.

\section{[Insert Table 1 about here]}

We assumed that all four quality variables are exogenously given. For-profit nursing homes are not fully regulated, since they can freely determine a part of their prices. Thus, they are theoretically not, or not entirely, financially constrained in their recruitment policy or in their investments in equipment.

\subsubsection{Chain Affiliation and Institutional Pressures}

Hypothesis 1 predicts that nursing home chain size does not influence cost efficiency. To explain estimated cost inefficiency scores, we departed from previous studies that analyzed the impact of chain affiliation using SFA (Anderson et al., 1999; Knox et al., 2001). Instead of using a mere dichotomous variable (chain vs. non-chain), we built a categorical Group variable. Group $=$ no if the facility is independent. Group $=$ medium if the chain includes no more than 50 facilities. Group = large if the chain includes more than 50 nursing homes. ${ }^{29}$

Hypothesis 2 states that local government pressure increases nursing home cost efficiency. We predict that some local authorities provide more incentives for cost containment than others, and exploit cross-county differences in two distinct ways to test Hypothesis 2. First, we defined a proxy for the generosity of the Conseil Général (see Section 3.2. for a reminder).

\footnotetext{
${ }^{28}$ We excluded nurses and physicians.

${ }^{29}$ This category includes nursing homes from the three largest groups in France: Korian-Medica, DVD, and Orpea.
} 
ElderlyExp is the ratio of total expenditures for aged people in the département to the number of people over the age of 75. Higher values of ElderlyExp are associated with greater generosity towards the elderly. We assume that more generous départements exert less pressure towards cost containment in nursing homes. We predict a positive sign for the coefficient associated with the ElderlyExp variable (i.e. a positive effect on cost inefficiency). Second, we added a Political variable. Political is coded 1 if the political party running the département in 2011 is right-wing, and 0 if it is left-wing. The idea behind the construction of this variable lies in preferences of political parties in France for some market organizations. The right-wing parties (e.g. Les Républicains) are usually assumed to support the development of market mechanisms and are in favor of a 'laissez-faire' style. Conversely, as Schedler (2003) notes, left-wing parties (e.g. the socialist party in France) are traditionally in favor of the welfare state and the public sector. Non-profit nursing homes are usually viewed as more trustworthy. They are considered as oriented more towards the meeting of social needs (Baum, 1999). As a result of government intervention, the leftist Conseils Généraux probably scrutinize for-profit nursing homes more than right-wing parties do. They may further restrict the regulated part of for-profit nursing homes' expenditures. Such control may result in lower inefficiency on the part of lucrative nursing homes. As a result, we predict a positive sign for the coefficient associated with the Political variable.

Hypothesis 3 assumes that shareholders' pressure increases nursing home cost efficiency. Pressures from shareholders are measured using a binary variable (Listed). It is coded 1 if the nursing home chain is listed, 0 otherwise. We expect a negative sign for the coefficient associated with Listed, since listed firms are subject to more pressures towards cost efficiency.

Hypothesis 4 predicts that nursing home market pressure results in cost efficiency. To measure each nursing home's market power, we built the MarketShare variable. MarketShare 
is equal to the number of beds of a nursing home divided by the total number of beds available ${ }^{30}$ within a $20 \mathrm{~km}$ radius ${ }^{31}$. When we have a chain-affiliated nursing home, beds of nursing homes belonging to the same chain around $20 \mathrm{~km}$ are added in the numerator. We expect a positive coefficient to be associated with the MarketShare variable.

Table 2 provides a description of all the variables.

\section{[Insert Table 2 about here]}

\section{Empirical Results}

\subsection{Descriptive Statistics}

We will report descriptive statistics for each variable included in the model and for each Group category in Table 3 . The daily average cost of a resident is higher for a chain-affiliated nursing home, especially when group size is important (€106.8 for independent nursing homes, $€ 109.3$ for small chains, and $€ 121.3$ for large chains).

Differences may be partially related to exogenous cost factors. For instance, chainaffiliated nursing homes are less often located in rural areas. They also often rent their buildings, which may be more expensive than owning them. However, chain-affiliated nursing homes receive slightly less dependent patients. In particular, they receive fewer residents classified as RUG 1 and RUG 2. Their quality of care is also smaller than independent facilities, which is consistent with the analysis by Harrington et al. (2001) on U.S. data. If all for-profit nursing homes are understaffed relative to their needs $(\operatorname{Staff}<1)$, the situation is even worse for nursing homes included in the largest chains: $80.3 \%$ of them have a staff-to-resident ratio below 0.75 . By comparison, this percentage is only $71.7 \%$ for independent facilities. Staff members in chain-affiliated nursing homes are also slightly less skilled. Nursing auxiliaries represent $54.2 \%$

\footnotetext{
${ }^{30} \mathrm{We}$ could also have considered used capacity (rather than mere capacity) to build the MarketShare variable. However, including such a variable could generate an endogeneity bias (Gulley \& Santerre, 2007). In addition, this variable differs very little from the capacity we use. Indeed, the average occupancy rate was equal to $94.1 \%$ in the private for-profit sector in 2011 (Martin, 2014).

${ }^{31}$ The (by road) $20 \mathrm{~km}$ radius seems to represent the size of the relevant market. When for-profit nursing homes are considered, $75 \%$ of the residents head towards nursing homes located within a $21 \mathrm{~km}$ radius (Martin, 2014).
} 
of staff members (except nurses and physicians) in independent nursing homes on average, while it is only $50.6 \%$ in medium-sized groups and $48.9 \%$ in large groups. All of these cost specificities confirm the importance of introducing explanatory variables of ownership, geographical situation, and quality into our cost model, in order to not assimilate them with inefficiency.

\section{[Insert Table 3 about here]}

\subsection{Influence of Chain Affiliation}

In Table 4, we present the estimation results of the cost frontier. We run all estimations using FRONTIER software (version 4.1). $\gamma$ is defined as the ratio of the variances of inefficiency and

residual terms $\left(\gamma=\frac{\sigma_{u}^{2}}{\sigma_{u}^{2}+\sigma_{v}^{2}}\right)$. It is statistically significant, which confirms our frontier model's relevance.

Since the dependent variable is the logarithm of annual costs, coefficients are interpreted as semi-elasticities (or elasticities for the log wage variables or variables expressed as a percentage). As expected, ResidentDays and the series of Wages variables have a significant positive impact on costs. As anticipated, costs are lower when residents are less dependent: coefficients associated with the $\% R U G$ variable are negative and increase (in absolute value) when the dependence level decreases (from RUG 1 to RUG 6). For instance, a 100\% increase in the number of patients belonging to the RUG 3 category (and a corresponding $100 \%$ decrease in the number of patients belonging to the RUG 1 category, which is the reference category) results in a $20.8 \%$ decrease in costs. Unsurprisingly, some environmental characteristics positively affect costs. Location in a big city generates additional costs. For instance, being located in Paris increases costs by $18.5 \%$, compared to a rural location. Other significant variables relate to a facility's features. For instance, ownership of buildings reduces costs by 3.8\%. Finally, quality variables Comfort, Staff, and \%MediumSkill have positive coefficients. 
For instance, regarding the Staff variable, a jump from 0.6 (or below) to the higher adjacent category results in a significant increase $(7.4 \%)$ in costs.

If all exogenous cost factors are taken into account by explanatory variables, the cost frontier is properly estimated. We treated the distance from each facility to the frontier (the asymmetric part of the residual) as cost inefficiency. The lower part of Table 4 shows that chainaffiliated nursing homes are significantly more inefficient than independent ones, ${ }^{32}$ since they are more distant to their cost frontier. Inefficiency differs across chains and is more important when nursing homes are affiliated to a large group (coefficient $=3.193$, significant at the $1 \%$ level for Group =large, compared to 0.304 for Group = medium). The empirical estimated values of the coefficients associated with the Group variables increase with chain size, which contradicts the argument that the larger sized chains or even the choice of adhering to a chain would be more cost-efficient. Results thus seem to suggest that chain organization may impose additional costs.

\section{[Insert Table 4 about here]}

This study helps to explain why we observe higher mean costs for large groups. On the one hand, exogenous costs (for instance, location in big cities and rental of buildings) generate a higher position on the cost frontier. On the other hand, large chains are located at a greater distance from the frontier, i.e. are more inefficient. A more rigid decision process or difficulties in integrating data processing systems may create inefficiency. Also, chains are prone to buy inefficient facilities (Menke, 1997). Thus, it takes time to achieve cost containment.

Actual and estimated (by the cost frontier) mean costs per resident-day are presented in Panel A of Table 5. The estimated mean costs slightly increase with chain size (it ranges from $€ 97.0$ for independent nursing homes to $€ 99.3$ for large chains). The actual mean costs follow the same trend, but the slope is steeper, going from $€ 106.8$ to $€ 121.3$. To deepen these results,

\footnotetext{
${ }^{32}$ Independent nursing homes are used as the reference category.
} 
we computed mean tests presented in Panels B and C. In Panel B of Table 5, we show that costs estimated with our model are not significantly higher for large chains. By contrast, Panel C of Table 5 shows that large chains incur significantly higher actual costs than independent nursing homes and medium-sized chains (mean tests are both significant at the $1 \%$ level). This implies that additional costs of nursing homes included in large chains mainly originate from cost inefficiency. As a result, large chains appear as particularly inefficient and strongly differ from the other two categories. We confirm this result by studying inefficiency scores in the next table.

\section{[Insert Table 5 about here]}

Descriptive statistics of estimated inefficiency scores are presented in Table 6. On average, for-profit nursing homes could reduce their costs by $11.7 \%{ }^{33}$ The average inefficiency is only $10.6 \%$ for members of medium-sized chains, while it rises to $21.1 \%$ for large groups. Differences in inefficiency scores between groups are partially confirmed by both parametric (t-test) and non-parametric (Kruskal-Wallis) tests. Independent nursing homes are not significantly more efficient than nursing homes affiliated to medium-sized groups. However, nursing homes affiliated to large groups are significantly less efficient than the other two groups.

\section{[Insert Table 6 about here]}

\subsection{Influence of the Institutional Environment}

We supplement the main result by studying the influence of three external pressures on the efficiency of for-profit nursing homes. This approach may help one to understand why chainaffiliated nursing homes are more cost-inefficient.

\footnotetext{
${ }^{33}$ This is a relative score computed from the comparison of for-profit nursing homes. The comparison of these institutions with public or private non-profit facilities could lead to higher or lower inefficiency scores. However, such a comparison is not possible, since we do not have homogeneous cost data for all statuses.
} 
First, we study the impact of political pressures on cost efficiency in Table 7 (column (a)). The inclusion of the ElderlyExp and Political variables does not affect the main result presented in the previous section: large chains are still significantly more cost-inefficient than others (coefficient $=2.280$ ). This is reinforced by two concurrent factors. As argued earlier, generous local authorities probably exert less pressure on nursing homes, resulting in higher cost inefficiency (coefficient $=1.645)$. For a given level of public generosity, we also observe that a local government's political stance affects cost efficiency. Right-wing local governments are associated with substantially higher cost inefficiency, compared to left-wing parties. This indicates that French for-profit nursing homes manage pressures from external stakeholders such as local governmental bodies.

Second, we observe in column (b) of Table 7 that listed nursing homes are more efficient than non-listed ones. Thus, shareholder pressure (approximated through listing status) diminishes large groups' inefficiency. On average, a nursing home affiliated to a large listed group is more efficient than an independent one, because the sum of coefficients associated with the Group $=$ large and Listed variables gives a negative result $(1.182-1.840=-0.658)$. To confirm our results, in column (d) of Table 7, we simultaneously present a regression including government, shareholder, and market pressures. The findings are similar.

Finally, when we include the MarketShare variable in the main regression in column (c) of Table 7, its coefficient is negative. This suggests that lower competitive pressures are associated with higher nursing home efficiency. At first sight, this result is striking. Nonetheless, we were able to find a reason for this surprising finding. Areas with low competitive pressure (mostly rural areas) are often located in poorer départements. The latter suffer from many financial constraints, which may prevent them from spending on much social assistance. This underlying mechanism is in line with empirical results. Indeed, when we added the ElderlyExp variable in column (d), the significant effect of the MarketShare variable on 
inefficiency disappeared. Another explanation may lie in the fact that listed nursing homes more often have strong market power. So the introduction of the Listed variable in column (d) makes the significance of the negative sign of the MarketShare variable disappear. It is difficult to explain why the MarketShare variable has no effect (column (d)). Market shares of nursing homes, as well as their heterogeneity, may be too low to enable a reasonable analysis of the effect of competition in France.

\section{[Insert Table 7 about here]}

\subsection{Robustness Checks}

We performed four additional robustness tests. First, we introduced a new specification by using a quantile regression method, instead of SFA (Koenker \& Basset, 1978). This is justified by the strong assumption we made on the distribution of the inefficiency term in SFA. The quantile regression $\mathrm{QR}(20 \%)$ assumes that the 20th percentile represents efficient nursing homes and allows for a cost frontier estimation. The quantile regression QR(10\%) with the 10th percentile is also carried out, as it is commonly assumed that $10 \%$ to $20 \%$ of nursing homes are efficient for frontier estimations with quantile regressions (Knox et al., 2007; Liu, Laporte, \& Ferguson, 2008). We present the results of $\mathrm{QR}(20 \%)$ and $\mathrm{QR}(10 \%)$ estimations in the first four columns of Table 8 .

\section{[Insert Table 8 about here]}

Although they are still positive (coefficient $=0.004$ for $\mathrm{QR}(20 \%$ ) and coefficient $=0.005$ for $\mathrm{QR}(10 \%))$, coefficients associated with nursing homes affiliated to medium-sized groups are not statistically significant. In this configuration, smaller chains have an efficiency level comparable to that of independent nursing homes. On the contrary, the coefficient associated with the inefficiency of large groups is still positive and significant at a $1 \%$ level (coefficient $=0.108$ for $\mathrm{QR}(20 \%)$ and coefficient $=0.092$ for $\mathrm{QR}(10 \%))$. Overall, this suggests that our main result is robust to the use of a different estimation technique. 
Second, we also tested chain size's impact on cost efficiency by using a continuous variable, instead of the Group indicator. We present the newly estimated coefficients and standard errors in Table 8. The coefficient associated with the continuous Group variable is positive and significant. This means that introducing a new facility into a chain increases the costs of its other nursing homes. As this effect is probably not linear, we used a categorical variable in the basic cost model instead. In addition, such a variable enables to compute inefficiency scores by types of groups.

Third, we tested whether the specification of the dependent variable influenced our results regarding Hypothesis 1. We built a new variable that equals the sum of operating expenses and interest expenses: COSTSbis. This allowed for a thorough comparison between nursing homes, as some rent their buildings while others own them. We did not include interest expenses in the main analyses, since they depend heavily on conditions of investment financing and may greatly vary from year to year for a given nursing home. We report results using the COSTSbis variable in Table 8. This modification does not change our inferences regarding Hypothesis 1.

Finally, in the last two columns of Table 8, we present SFA results where the ActivityLength variable is replaced by BuildAge. BuildAge is the number of years since the latest renovation (if not, we use construction) of the building. We substitute BuildAge for ActivityLength to isolate equipment age's effect on costs without considering potential cost reduction attributable to staff learning by doing. Similarly to the ActivityLength variable, the BuildAge variable is not significantly correlated with costs. This change did not affect our main result: coefficients associated with nursing homes affiliated to medium-sized and large groups were positive and statistically significant (coefficient $=0.685$ for medium-sized chains and coefficient $=3.169$ for large chains).

\section{Discussion and Conclusion}


This study provides empirical evidence of substantially higher costs in French for-profit nursing home chains, compared to their independent counterparts. We show that increased costs are driven by higher cost inefficiency, especially for large chains. The consolidation movement in the nursing home industry does not lead to economies of scale, but rather seems to generate important diseconomies of scale for the largest chains. This is not beneficial for society and particularly affects residents whose out-of-pocket payments will increase.

Chain-affiliated nursing homes may be less prone to containing costs for some reasons that are difficult to measure and document. First, higher cost inefficiency may originate from multi-unit coordination difficulties and more complex decision-making processes. In newly acquired units, the adoption of practices not adapted to the local context, failure to account for pre-existing culture, and high standardization levels can negatively affect nursing homes and generate higher costs (Banaszak-Holl, Berta, Bowman, Baum, \& Mitchell, 2002). Second, nursing homes may opt for different competitive strategies. Higher prices observed in large chains $^{34}$ suggest these nursing homes chose a differentiation strategy, although there is no empirical evidence of higher quality levels. For instance, a chain's commercial reputation is probably a key selling point, which allows chains to set higher prices. According to economic theory, for-profit nursing homes seek profit maximization above all, and thus cost minimization. As a result, their strategic choice should have no impact on their cost inefficiency. However, in reality, in business, chain nursing homes' ability to set higher prices probably does not incentivize them to minimize their costs. The matter of prices (and margins) goes beyond our research questions, which are limited only to costs. This underlying broader question deserves further investigation. Third, there is a high interdependency between multiunit chain components and the chain (Chuang \& Baum, 2003). Since chain nursing homes

\footnotetext{
${ }^{34}$ The average price for a resident-day is $€ 93.9$ for independent nursing homes, $€ 107.6$ for medium-sized groups, and $€ 119.7$ for large chains.

Sources: own computation from DIANE and 2011 EHPA survey (DREES) (sample of 370 nursing homes).
} 
usually use the same name in France (or at least develop commercial arguments around the chain name), one unit's failure can negatively impact an entire chain. This generates an underlying solidarity from the parent company. It can lower cost containment incentives, since facilities know they will be supported as a last resort if they encounter problems.

We further report on how external pressures from the institutional environment influence cost inefficiency. In particular, we demonstrate that the nursing homes included in our sample respond to pressures from public equity by improving their cost efficiency. Other forces, such as private equity (PE), may also potentially affect cost efficiency. The health care services sector became increasingly attractive for PE investment funds (Robbins, Rudsenske, \& Vaughan, 2008). PE's strategic policy may be focused on cutting costs - and thus on cost efficiency - to improve nursing homes' financial results (Harrington, Olney, Carrillo, \& Kang, 2012). Future studies could assess the influence of this type of investors on cost efficiency. We also demonstrate that our nursing homes respond to varying pressures from local regulatory authorities. This is consistent with the study of Holzhacker et al. (2015) who use a German hospital sample to show that for-profit organizations are more likely to respond to changes in regulation than non-profit ones as the for-profit sector experiences increased pressure to demonstrate its capacity to generate profits.

Like other empirical studies of nursing homes, our results are subject to the following caveats. First, we use no specific criterion to select observations. Therefore, there is no systematic selection bias: the nursing homes included in our sample do not exhibit any specific features. However, for each nursing home category in our sample, we are unable to meet exactly the same proportion as in the true population.

Second, we use a parametric estimation method and decompose total costs in two parts: costs attributed to exogenous conditions and costs related to inefficiency. The robustness of our results relies on a good specification of the cost model (Kumbhakar \& Knox Lovell, 2000). 
However, although we include a large set of independent variables, we are unable to control for all cost specificities. For instance, our urbanization variable (Urb) does not capture price variations for different areas located in the same town or city. This limitation may have biased our inefficiency scores and may have influenced our conclusions.

Third, we identify nursing home chains based on their ownership structure. Our classification requires a nursing home to be formally identified as legally belonging to a group of nursing homes. However, this criterion does not consider cooperation programs that some groups may informally create. Some independent facilities may cluster using more flexible coordination mechanisms. For instance, Résidéal Santé runs a pool of nursing homes without any financial links. Résidéal Santé's facilities are considered as independent in our research design, when they could probably, to some extent, be considered as related. Since nursing homes do not clearly identify this behavior, it is not available in the database we used. This limitation would require individual patient history to trace cluster strategy and to allow finer comparisons across nursing home chains. 


\section{References}

Aaronson, W. E., Zinn, J. S., \& Rosko, M. D. (1994). Do for-profit and not-for-profit nursing homes behave differently? The Gerontologist, 34, 775-786. doi: 0.1093/geront/34.6.775

Abernethy, M. A., \& Chua, W. F. (1996). A field study of control system "redesign": The impact of institutional processes on strategic choice. Contemporary Accounting Research, 13, 569-606. doi: 10.1111/j.1911-3846.1996.tb00515.x

Abernethy, M. A., \& Vagnoni, E. (2004). Power, organization design and managerial behaviour. Accounting, Organizations and Society, 29, 207-225. doi: 10.1016/S03613682(03)00049-7

Aigner, D., Knox Lovell, C. A., \& Schmidt, P. (1977). Formulation and estimation of stochastic frontier production models. Journal of Econometrics, 6, 21-37. doi: $10.1016 / 0304-4076(77) 90052-5$

Anderson, R., Lewis, D., \& Webb, J. (1999). The efficiency of nursing home chains and the implications of non-profit status. Journal of Real Estate Portfolio Management, 5, 235245. doi: 10.5555/repm.5.3.m62t73u3518613u1

Anderson, R. I., Weeks, H. S., Hobbs, B. K., \& Webb, J. R. (2003). Nursing home quality, chain affiliation, profit status and performance. Journal of Real Estate Research, 25, 43-60. Retrieved from http://papers.ssrn.com/sol3/papers.cfm?abstract_id=981258

Banaszak-Holl, J., Berta, W. B., Baum, J., \& Mitchell, W. (2002). Comparing service and quality among chain and independent US nursing homes during the 1990s (Working Paper). University of Michigan, University of Toronto, and Duke University. Retrieved from https://centers.fuqua.duke.edu/case/wpcontent/uploads/sites/7/2015/03/Article_BanaszakHoll_Berta_Baum_Mitchell_ComparingServiceAndQualityAmongChainandIndepende ntUSNursingHomesDuringthe1990s_2002.pdf 
Banaszak-Holl, J., Berta, W. B., Bowman, D. M., Baum, J. A. C., \& Mitchell, W. (2002). The rise of human service chains: Antecedents to acquisitions and their effects on the quality of care in US nursing homes. Managerial and Decision Economics, 23:261-282. doi: $10.1002 /$ mde. 1065

Banker, R. D., \& Morey, R. C. (1986). The use of categorical variables in data envelopment analysis. Management Science, 32, 1613-1627. doi: 10.1287/mnsc.32.12.1613

Battese, G. E., \& Coelli, T. J. (1995). A model for technical efficiency effects in a stochastic frontier production function for panel data. Empirical Economics, 20, 325-332. doi: 10.1007/BF01205442

Baum, J. A. C. (1999). The rise of chain nursing homes in Ontario, 1971-1996. Social Forces, 78, 543-584. doi: 10.1093/sf/78.2.543

Brignall, S., \& Modell, S. (2000). An institutional perspective on performance measurement and management in the 'new public sector'. Management Accounting Research, 11, 281-306. doi: 10.1006/mare.2000.0136

Cardinaels, E. (2009). Governance in non-for-profit hospitals: Effects of board members' remuneration and expertise on CEO compensation. Health Policy, 93, 64-75. doi: 10.1016/j.healthpol.2009.07.001

Cardinaels, E., Roodhooft, F., \& Van Herck, G. (2004). Drivers of cost system development in hospitals: Results of a survey. Health Policy, 69, 239-252. doi:

10.1016/j.healthpol.2004.04.009

Cardinaels, E., \& Soderstrom, N. (2013). Managing in a complex world: Accounting and governance choices in hospitals. European Accounting Review, 22, 647-684. doi: $10.1080 / 09638180.2013 .842493$ 
Carmona, S., \& Macías, M. (2001). Institutional pressures, monopolistic conditions and the implementation of early cost management practices: The case of the royal tobacco factory of Seville (1820-1887). Abacus, 37, 139-165. doi: 10.1111/1467-6281.00080

Chang, H., Chang, W.-J., Das, S., \& Li, S.-H. (2004). Health care regulation and the operating efficiency of hospitals: Evidence from Taiwan. Journal of Accounting and Public Policy, 23, 483-510. doi: 10.1016/j.jaccpubpol.2004.10.004

Chen, C.-M., Delmas, M. A., \& Lieberman, M. B. (2015). Production frontier methodologies and efficiency as a performance measure in strategic management research. Strategic Management Journal, 36, 19-36. doi: 10.1002/smj.2199

Christensen, E. W. (2004). Scale and scope economies in nursing homes: A quantile regression approach. Health Economics, 13, 363-377. doi: 10.1002/hec.828

Chua, W. F., \& Preston, A. (1994). Worrying about accounting in health care. Accounting, Auditing \& Accountability Journal, 7(3), 4-17. doi: 10.1108/09513579410064097

Chuang, Y.-T., \& Baum, J. A. C. (2003). It's all in the name: Failure-induced learning by multiunit chains. Administrative Science Quaterly, 48, 33-59. doi: 10.2307/3556618

Coelli, T. J., Estache, A., Perelman, S., \& Trujillo, L. (2003). A primer on efficiency measurement for utilities and transport regulators. Washington, DC: World Bank. doi: $10.1596 / 0-8213-5379-9$

Coelli, T. J., Rao, D. S. P., O’Donnell, C. J., \& Battese, G. E. (2005). An introduction to efficiency and productivity analysis (2nd ed.). New York: Springer. doi: 10.1007/978-14615-5493-6

Cohen, J. W., \& Spector, W. D. (1996). The effect of Medicaid reimbursement on quality of care in nursing homes. Journal of Health Economics, 15, 23-48. doi: 10.1016/01676296(95)00030-5 
Comondore, V. R., Devereaux, P. J., Zhou, Q., Stone, S. B., Busse, J. W., Ravindran,N. C. ... \& Guyatt, G. H. (2009). Quality of care in for-profit and not-for-profit nursing homes: Systematic review and meta-analysis. British Medical Journal, 339, 1-15. doi: $0.1136 /$ bmj.b2732

Covaleski, M. A., Dirsmith, M. W., \& Samuel, S. (1996). Managerial accounting research: The contribution of organizational and sociological theories. Journal of Management Accounting Research, 8, 1-36. Retrieved from http://www.ebscohost.com

Dewaelheyns, N., Eeckloo, K., Van Herck, G., Van Hulle, C., \& Vleugels, A. (2009). Do nonprofit nursing homes separate governance roles? The impact of size and ownership characteristics. Health Policy, 90, 188-195. doi: 10.1016/j.healthpol.2008.09.014

Di Giorgio, L., Filippini, M., \& Masiero, G. (2014). The relationship between costs and quality in nonprofit nursing homes (Working Paper). University of Washington, Swiss Federal Institute of Technology in Zurich, University of Bergamo, and Università della Svizzera italiana. Retrieved from http://doc.rero.ch/record/209725/files/WP1402.pdf Dormont, B., \& Martin, C. (2012, January). Quality of service and cost-efficiency of French nursing homes. Paper presented at the 3rd joint CES/HESG Workshop of Collège des Economistes de la Santé and Health Economists' Study Group, Aix-en-Provence. Retrieved from http://www.ces-asso.org/sites/default/files/Dormont_Martin_HESG.pdf Direction de la Recherche, des Études, de l'Évaluation et des Statistiques. (2014). L'offre en établissements d'hébergement pour personnes âgées en 2011 [The supply of nursing homes for the elderly in 2011]. Retrieved from http://drees.socialsante.gouv.fr/IMG/pdf/er877.pdf

Eldenburg, L., Hermalin, B. E., Weisbach, M. S., \& Wosinska, M. (2004). Governance, performance objectives and organizational form: Evidence from hospitals. Journal of Corporate Finance, 10, 527-548. doi: 10.2139/ssrn.236106 
Eldenburg, L., \& Krishnan, R. (2003). Public versus private governance: A study of incentives and operational performance. Journal of Accounting and Economics, 35, 377-404. doi: 10.1016/S0165-4101(03)00038-7

Ernst \& Young (2008). Étude sur le marché de l'offre de soins, d'hébergement et de services destinés aux personnes âgées dépendantes [Study on the supply market of nursing care, lodging, and services for the dependent elderly]. Retrieved from http://www.senat.fr/commission/missions/Dependance/etude.pdf

European Commission (2008). Long-term care in European Union. Luxembourg: Office for Official Publications of the European Communities. doi: 10.2767/30206

Ewing, B. T., Kruse, J. B., \& Thompson, M. A. (2005). Comparing the impact of news: A tale of three health care sectors. Journal of Business Finance \& Accounting, 32, 15871611. doi: 10.1111/j.0306-686X.2005.00641.x

Farsi, M., \& Filippini, M. (2004). An empirical analysis of cost efficiency in non-profit and public nursing homes. Annals of Public and Corporative Economics, 75, 339-365. doi: $10.1111 / \mathrm{j} .1467-8292.2004 .00255 . \mathrm{x}$

Fizel, J. L., \& Nunnikhoven, T. S. (1993). The efficiency of nursing home chains. Applied Economics, 25, 49-55. doi: 10.1080/00036849300000112

Forder, J., \& Allan, S. (2011). Competition in the English nursing homes market (Discussion Paper No. 2820). Canterbury: ESHCRU. Retrieved from http://www.pssru.ac.uk/archive/pdf/dp2820.pdf

Gibson, D. E., \& Barsade, S. G. (2003). Managing organizational culture change: The case of long-term care. Journal of Social Work in Long-Term Care, 2, 11-34. doi: 10.1300/J181v02n01_02 
Grabowski, D. C., Feng, Z., Hirth, R., Rahman, M., \& Mor, V. (2013). Effect of nursing home ownership on the quality of post-acute care: An instrumental variables approach. Journal of Health Economics, 32, 12-21. doi: 10.1016/j.jhealeco.2012.08.007

Gulley, O. D., \& Santerre, R. (2007). Market structure elements: The case of California nursing homes. Journal of Health Care Finance, 33, 1-16. Retrieved from http://www.ncbi.nlm.nih.gov/pubmed/19172959

Harrington, C., Woolhandler, S., Mullan, J., Carillo, H., \& Himmelstein, D. U. (2001). Does investor ownership of nursing homes compromise the quality of care? American Journal of Public Health, 91, 1452-1455. doi: 10.2105/AJPH.91.9.1452

Harrington, C., Olney, B., Carrillo, H., \& Kang, T. (2012). Nurse staffing and deficiencies in the largest for-profit nursing home chains and chains owned by private equity companies, Health Services Research, 47, 106-128. doi: 10.1111/j.1475$6773.2011 .01311 . x$

Holzhacker, M., Krishnan, R., \& Malhendorf, M. D. (2015). The impact of changes in regulation on cost behavior. Contemporary Accounting Research, 32, 534-566. doi:10.1111/1911-3846.12082

Hsu, S. H., \& Qu, S. Q. (2012). Strategic cost management and institutional changes in hospitals. European Accounting Review, 21, 499-531. doi:

$10.1080 / 09638180.2012 .658152$

Ingram, P., \& Baum, J. A. C. (1997). Chain affiliation and the failure of Manhattan hotels, 1898-1980, Administrative Science Quarterly, 42, 68-102. doi: 10.2307/2393809

Jondrow, J., Knox Lovell, C. A., Masterov, I. S., \& Schmidt, P. (1982). On the estimation of technical inefficiency in the stochastic frontier production function model. Journal of Econometrics, 19, 233-238. doi: 10.1016/0304-4076(82)90004-5 
Knox, K., Blankmeyer, E., \& Stutzman, J. (2001). The efficiency of nursing home chains and the implications on nonprofit status: A comment. Journal of Real Estate Portfolio Management, 7, 177-182. doi: 10.5555/repm.7.2.j1423864g55214xh

Knox, K. J., Blankmeyer, E. C., \& Stutzman, J. R. (2007). Technical efficiency in Texas nursing facilities: A stochastic production frontier approach. Journal of Economics and Finance, 31, 75-86. doi: 10.1007/BF02751513

Koenker, R., \& Basset, G. (1978). Regression quantiles. Econometrica, 46, 33-50. doi: $10.2307 / 1913643$

Korian (2011). Korian corporate report. Retrieved from http://www.korian.com/globalassets/documents/korian---document-de-reference-2011 Korian (2013). Korian corporate report. Retrieved from http://www.korian.com/globalassets/documents/document-de-reference-2013

Krishnan, R. (2005). The effect of changes in regulation and competition on firms' demand for accounting information. The Accounting Review, 80, 269-287. doi: 10.2308/accr.2005.80.1.269

Kumbhakar, S. C., \& Knox Lovell, C. A. (2000). Stochastic frontier analysis. Cambridge: Cambridge University Press. doi: 10.1017/CBO9781139174411

Lafontaine, F., \& Slade, M. (2007). Vertical integration and firm boundaries: The evidence. Journal of Economic Literature, 45, 629-685. doi: 10.1257/jel.45.3.629

Lelong, P., \& Jacquet, D. (2012). Le guide de la dépendance 2012 - Mieux vivre le 4ème âge et le handicap [The 2012 dependence guide - Living better as senior citizens and with a handicap]. Paris: JTL Éditions: FranceInfo.

Létard, V., Flandre, H., \& Lepeltier, S. (2004). La France et les Français face à la canicule : les leçons d'une crise [France and the French facing the heatwave: Lessons from a crisis] (Report No. 195). Retrieved from http://www.senat.fr/rap/r03-195/r03-1951.pdf 
Lipszyc, B., Sail, E., \& Xavier, A. (2012). Long-term care: Need, use and expenditure in the EU-27 (Economic papers No. 469). Brussels: European Commission. doi: $10.2765 / 27485$

Liu, C., Laporte, A., \& Ferguson, B. S. (2008). The quantile regression approach to efficiency measurement: Insights from Monte Carlo simulations. Health Economics, 17, 10731087. doi: $10.1002 /$ hec. 1398

Lu, S. F., \& Wedig, G. J. (2013). Clustering, agency costs and operating efficiency: Evidence from nursing home chains. Management Science, 59, 677-694. doi: $10.1287 / \mathrm{mnsc} .1120 .1611$

Margaritis, D., \& Psillaki, M. (2007). Capital structure and firm efficiency. Journal of Business Finance \& Accounting, 34, 1447-1469. doi: 10.1111/j.14685957.2007.02056.x

Martin, C. (2014). Concurrence, prix et qualité de la prise en charge en EHPAD en France : Analyses micro-économétriques [Competition, prices, and quality of care in French nursing homes: Microeconometric analyses] (Unpublished doctoral dissertation). ParisDauphine University, Paris.

McKay, N. L. (1991). The effect of chain ownership on nursing home costs. Health Services Research, 26, 109-124. Retrieved from http://www.ncbi.nlm.nih.gov/pmc/articles/PMC1069813/pdf/hsresearch00070-0114.pdf

Meeusen, W., \& van den Broeck, J. (1977). Efficiency estimation from Cobb-Douglas production functions with composed error. International Economic Review, 18, 435444. doi: $10.2307 / 2525757$

Menke, T. J. (1997). The effect of chain membership on hospital costs. Health Services Research, 32, 177-196. Retrieved from http://www.ncbi.nlm.nih.gov/pmc/articles/PMC1070180/ 
Newhouse, J. P. (1970). Toward a theory of nonprofit institutions: An economic model of a hospital. American Economic Review, 60, 64-74. Retrieved from http://www.ebscohost.com

Newhouse, J. P. (1994). Frontier estimation: How useful a tool for health economics? Journal of Health Economics, 13, 317-322. doi: 10.1016/0167-6296(94)90030-2

Orpea (2014). Retrieved from http://www.orpea.com

Ratte, E., \& Imbaud, D. (2011). Accueil et accompagnement des personnes âgées en perte d'autonomie [Support and care for the elderly suffering from a loss of autonomy]. Paris: Ministère des solidarités et de la cohésion sociale. Retrieved from http://www.ladocumentationfrancaise.fr/var/storage/rapports-publics/114000334.pdf Réjault, W. (2011). Maman, est-ce que ta chambre te plaît? Survivre en maison de retraite [Mommy, do you like your bedroom? Surviving in a nursing home] (2nd ed.). Paris: J'ai lu.

Robbins, C. J., Rudsenske, T., \& Vaughan, J. S. (2008). Private equity investment in health care services. Health Affairs, 27, 1389-1398. doi: 10.1377/hlthaff.27.5.1389

Roberts, R. W. (1998). A stakeholder approach to the corporate single audit. Critical Perspectives on Accounting, 9, 227-232. doi: 10.1006/cpac.1997.0171

Schedler, K. (2003). Local and regional public management reforms in Switzerland. Public Administration, 81, 325-344. doi: 10.1111/1467-9299.00349

Shyu, J. (2013). Ownership structure, capital structure, and performance of group affiliation: Evidence from Taiwanese group-affiliated firms. Managerial Finance, 39, 404-420. doi: $10.1108 / 03074351311306210$

Smith, H. L., \& Fottler, M. D. (1981). Costs and cost containment in nursing homes. Health Service Research, 16(1):17-41. Retrieved from http://www.ncbi.nlm.nih.gov/pmc/articles/PMC1072210/pdf/hsresearch00530-0017.pdf 
Van Peursem, K. A., Pratt, M. J., \& Lawrence, S. R. (1995). Health management performance: A review of measures and indicators. Accounting, Auditing \& Accountability Journal, 8(5), 34-70. doi: 10.1108/09513579510103254

Vitaliano, D., \& Toren, M. (1994). Cost and efficiency in nursing homes: a stochastic frontier approach. Journal of Health Economics, 13, 281-300. http://dx.doi.org/10.1016/0167$6296 \% 2894 \% 2990028-0$

Wang, H.-J., \& Schmidt, P. (2002). One-step and two-step estimation of the effects of exogenous variables on technical efficiency levels. Journal of Productivity Analysis, 18, 129-144. Retrieved from http://www.ebscohost.com

Weech-Maldonado, R., Shea, D., \& Mor, V. (2006). The relationship between quality of care and costs in nursing homes. American Journal of Medical Quality, 21, 40-48. doi: $10.1177 / 1062860605280643$ 
Table 1. Methodology Used to Build the Comfort Variable

\begin{tabular}{|c|c|c|}
\hline Categories & Points & Details \\
\hline \multirow[t]{2}{*}{ Environment quality } & 10 & \\
\hline & & $\begin{array}{l}10 \text { points if the nursing home is located near services/local shops }(<500 \mathrm{~m}) \\
\text { or } 0 \text { points otherwise }\end{array}$ \\
\hline \multirow[t]{2}{*}{ Building quality } & 15 & \\
\hline & & $\begin{array}{l}15 \text { points if years since renovation/construction } \leq 5 \\
\text { or } 10 \text { points if years } \leq 10(\text { and }>5) \\
\text { or } 5 \text { points if years } \leq 20(\text { and }>10) \\
\text { or } 0 \text { points if years }>20\end{array}$ \\
\hline \multirow[t]{2}{*}{$\begin{array}{l}\text { Quality of the living } \\
\text { and care areas }\end{array}$} & 25 & \\
\hline & & $\begin{array}{l}2 \text { points if there is a living room } \\
+2 \text { points if there is a welcome room for families } \\
+2 \text { points if space is provided for activities } \\
+2 \text { points if there is a separate TV area } \\
+2 \text { points if there is access to a hairdresser } \\
+2 \text { points if there is an Internet access } \\
+2 \text { points if there is an area for a kinetic therapist } \\
+2 \text { points if there are end-of-life rooms } \\
+2 \text { points if there is a multisensory space (Snoezelen room) } \\
+2 \text { points if there are patient lifts } \\
+5 \text { points if there are allocated dining areas }\end{array}$ \\
\hline \multirow[t]{2}{*}{ Room comfort } & 20 & \\
\hline & & $\begin{array}{l}10 \text { points } *(x \% \text { of single rooms }) \\
10 \text { points } *\left(x \% \text { of single rooms }>20 \mathrm{~m}^{2}\right)\end{array}$ \\
\hline \multirow[t]{2}{*}{ Equipment in rooms } & 25 & \\
\hline & & $\begin{array}{l}5 \text { points } *(x \% \text { of rooms with a toilet }) \\
+5 \text { points } *(x \% \text { of rooms with a washbasin }) \\
+2.5 \text { points } *(x \% \text { of rooms with a shower }) \\
+5 \text { points } *(x \% \text { of rooms with a phone jack }) \\
+5 \text { points } *(x \% \text { of rooms with a TV socket }) \\
+2.5 \text { points } *(x \% \text { of rooms with air-conditioning })\end{array}$ \\
\hline \multirow[t]{2}{*}{ Green area } & 5 & \\
\hline & & $\begin{array}{l}5 \text { points if there is a garden } \\
\text { or } 0 \text { points otherwise }\end{array}$ \\
\hline \multirow[t]{2}{*}{ Accessibility } & 20 & \\
\hline & & $\begin{array}{l}2 \text { points } *(x \% \text { of rooms with a specific signage }) \\
+2 \text { points } *(x \% \text { of rooms with wheelchair access }) \\
+2 \text { points } *(x \% \text { of rooms with access to hospital beds }) \\
+2 \text { points } *(x \% \text { of rooms with a toilet suitable for a wheelchair }) \\
+2 \text { points } *(x \% \text { of rooms with a shower suitable for a wheelchair }) \\
+2 \text { points } *(x \% \text { of rooms with a washbasin accessible in a seated position }) \\
+2 \text { points } *(x \% \text { of rooms with electric blinds }) \\
+2 \text { points } *(x \% \text { of rooms with switches that are accessible without bending down }) \\
+2 \text { points if corridors are lit all the time or if there is a presence detector } \\
+2 \text { points if medical beds are accessible by elevator }\end{array}$ \\
\hline
\end{tabular}

Note: This table presents the items and their weightings included in the grid used to build the Comfort variable. We are inspired from the method and weightings used by a French agency, France Info, who conducted a quality investigation among French nursing homes (Lelong \& Jacquet, 2012). The minimum value is zero and the maximum value is 120. The Comfort variable is one of the control variable $z_{k}$ included in equation (1):

$$
\ln \text { COSTS }=\alpha_{0}+\alpha_{R D} \text { ResidentDays }+\alpha_{R D^{2}} \text { ResidentDays }^{2}+\sum_{i} \alpha_{w_{i}} \ln \left(\text { Wages }_{i}\right)+\sum_{k} \alpha_{z_{k}} z_{k}
$$


Table 3. Descriptive Statistics

\begin{tabular}{|c|c|c|c|c|c|c|c|c|c|}
\hline \multirow{2}{*}{ Variables } & \multicolumn{3}{|c|}{ Group $=$ no } & \multicolumn{3}{|c|}{ Group $=$ medium } & \multicolumn{3}{|c|}{ Group = large } \\
\hline & Median & Mean & $\left(\sigma^{2}\right)$ & Median & Mean & $\left(\sigma^{2}\right)$ & Median & Mean & $\left(\sigma^{2}\right)$ \\
\hline COSTS (in thousands of $€$ ) & $2,175.0$ & $2,255.0$ & $(991.0)$ & $2,665.0$ & $2,627.4$ & $(802.5)$ & $2,957.0$ & $3,070.6$ & $(1,205.0)$ \\
\hline ResidentDays & 21,170 & 21,153 & $(8,090)$ & 25,550 & 24,299 & $(6,927)$ & 25,185 & 25,420 & $(7,529)$ \\
\hline COSTS/ResidentDays & 104.1 & 106.8 & $(20.85)$ & 106.5 & 109.3 & $(20.11)$ & 116.6 & 121.3 & $(25.24)$ \\
\hline $\operatorname{Wages}_{N}$ & 33,830 & 34,091 & $(4,587)$ & 34,031 & 34,232 & $(4,193)$ & 35,135 & 35,178 & $(4,184)$ \\
\hline Wages $_{N A}$ & 22,571 & 22,730 & $(1,573)$ & 22,970 & 22,822 & $(1,754)$ & 22,710 & 22,900 & $(1,295)$ \\
\hline Wagesss & 20,119 & 20,292 & $(1,107)$ & 20,756 & 20,858 & $(1,059)$ & 20,523 & 20,662 & $(762.2)$ \\
\hline$\%$ RUG1 & $18.7 \%$ & $20.1 \%$ & $(0.109)$ & $18.2 \%$ & $20.4 \%$ & $(0.098)$ & $17.6 \%$ & $18.0 \%$ & $(0.080)$ \\
\hline \%RUG2 & $37.7 \%$ & $39.0 \%$ & $(0.110)$ & $37.5 \%$ & $38.1 \%$ & $(0.103)$ & $36.5 \%$ & $37.0 \%$ & $(0.078)$ \\
\hline$\%$ RUG3 & $16.0 \%$ & $16.1 \%$ & $(0.072)$ & $14.7 \%$ & $15.5 \%$ & $(0.073)$ & $18.2 \%$ & $18.0 \%$ & $(0.062)$ \\
\hline$\%$ RUG4 & $17.2 \%$ & $17.5 \%$ & $(0.081)$ & $17.9 \%$ & $18.0 \%$ & $(0.085)$ & $17.9 \%$ & $18.8 \%$ & $(0.075)$ \\
\hline \%RUG5 & $3.4 \%$ & $4.1 \%$ & $(0.041)$ & $3.6 \%$ & $4.3 \%$ & $(0.035)$ & $4.9 \%$ & $5.3 \%$ & $(0.040)$ \\
\hline \%RUG6 & $2.0 \%$ & $3.2 \%$ & $(0.046)$ & $2.3 \%$ & $3.6 \%$ & $(0.045)$ & $1.7 \%$ & $2.8 \%$ & $(0.034)$ \\
\hline ActivityLength & 21.0 & 21.5 & $(15.0)$ & 19.0 & 21.4 & $(18.8)$ & 18.0 & 22.4 & $(22.5)$ \\
\hline Attract & $3.05 \%$ & $6.58 \%$ & $(0.094)$ & $2.12 \%$ & $3.96 \%$ & $(0.057)$ & $2.19 \%$ & $5.38 \%$ & $(0.109)$ \\
\hline Comfort & 85.3 & 83.3 & $(14.75)$ & 89.0 & 87.1 & (11.75) & 83.3 & 83.5 & (12.8) \\
\hline \%HighSkill & $15.8 \%$ & $17.7 \%$ & $(0.078)$ & $14.3 \%$ & $16.7 \%$ & $(0.083)$ & $15.0 \%$ & $17.6 \%$ & $(0.085)$ \\
\hline$\%$ MediumSkill & $52.1 \%$ & $54.2 \%$ & $(0.181)$ & $49.2 \%$ & $50.6 \%$ & $(0.160)$ & $49.7 \%$ & $48.9 \%$ & $(0.175)$ \\
\hline ElderlyExp & 1.110 & 1.150 & $(0.186)$ & 1.134 & 1.132 & $(0.149)$ & 1.138 & 1.171 & $(0.2123)$ \\
\hline \multirow[t]{2}{*}{ MarketShare } & $2.19 \%$ & $3.13 \%$ & $(0.031)$ & $4.00 \%$ & $4.70 \%$ & $(0.035)$ & $8.19 \%$ & $9.16 \%$ & $(0.130)$ \\
\hline & $\mathrm{N}$ & $(\%)$ & & $\mathrm{N}$ & $(\%)$ & & $\mathrm{N}$ & $(\%)$ & \\
\hline PartiallyRegulated $=$ no & 177 & $74.7 \%$ & & 63 & $81.8 \%$ & & 43 & $76.8 \%$ & \\
\hline PartiallyRegulated $=$ yes & 60 & $25.3 \%$ & & 14 & $18.2 \%$ & & 13 & $23.2 \%$ & \\
\hline Drugstore $=$ no & 233 & $98.3 \%$ & & 76 & $98.7 \%$ & & 56 & $100.0 \%$ & \\
\hline Drugstore $=$ yes & 4 & $1.7 \%$ & & 1 & $1.3 \%$ & & 0 & $0.0 \%$ & \\
\hline PriceOption $=$ partial & 206 & $86.9 \%$ & & 65 & $84.4 \%$ & & 40 & $71.4 \%$ & \\
\hline PriceOption = global & 31 & $13.1 \%$ & & 12 & $15.6 \%$ & & 16 & $28.6 \%$ & \\
\hline BuildOwn $=$ rental & 117 & $49.4 \%$ & & 51 & $66.2 \%$ & & 38 & $67.9 \%$ & \\
\hline BuildOwn = owner & 120 & $50.6 \%$ & & 26 & $33.8 \%$ & & 18 & $32.1 \%$ & \\
\hline Urb: inhab $<20,000$ & 149 & $20.7 \%$ & & 16 & $20.8 \%$ & & 7 & $12.5 \%$ & \\
\hline Urb: $20,000 \leq$ inhab $<200,000$ & 53 & $22.4 \%$ & & 13 & $16.9 \%$ & & 15 & $26.8 \%$ & \\
\hline Urb: $200,000 \leq$ inhab $<500,000$ & 23 & $9.7 \%$ & & 10 & $13.0 \%$ & & 7 & $12.5 \%$ & \\
\hline Urb: $500,000 \leq$ inhab $<1,000,000$ & 78 & $32.9 \%$ & & 29 & $37.6 \%$ & & 5 & $8.9 \%$ & \\
\hline Urb: Paris & 34 & $14.3 \%$ & & 9 & $11.7 \%$ & & 22 & $39.3 \%$ & \\
\hline Staff: $N / N^{*}<0.6$ & 56 & $23.6 \%$ & & 18 & $23.4 \%$ & & 12 & $21.4 \%$ & \\
\hline Staff: $0.6 \leq N / N^{*}<0.75$ & 114 & $48.1 \%$ & & 37 & $48.0 \%$ & & 33 & $58.9 \%$ & \\
\hline Staff: $0.75 \leq N / N^{*}<0.95$ & 61 & $25.8 \%$ & & 21 & $27.3 \%$ & & 9 & $16.1 \%$ & \\
\hline Staff: $0.95 \leq N / N^{*}$ & 6 & $2.5 \%$ & & 1 & $1.3 \%$ & & 2 & $3.6 \%$ & \\
\hline Political $=$ left & 125 & $52.7 \%$ & & 45 & $58.4 \%$ & & 36 & $64.3 \%$ & \\
\hline Political $=$ right & 112 & $47.3 \%$ & & 32 & $41.6 \%$ & & 20 & $35.7 \%$ & \\
\hline Listed $=$ no & 237 & $100 \%$ & & 76 & $98.7 \%$ & & 46 & $82.1 \%$ & \\
\hline Listed $=$ yes & 0 & $0 \%$ & & 1 & $1.3 \%$ & & 10 & $17.9 \%$ & \\
\hline $\mathbf{N}$ & & 237 & & & 77 & & & 56 & \\
\hline
\end{tabular}

Note: This table presents descriptive statistics (the median, the mean, and the standard deviation $\left(\sigma^{2}\right)$ ) for the variables used in the analysis. The sample consists of 370 French for-profit nursing homes in 2011. The sample is split depending on the size of the group they belong to: no group, medium group or large group.

We obtained most of data from the 2011 EHPA survey elaborated by DREES except the following ones: COSTS is computed from DIANE, Attract, Urb, and ElderlyExp are computed from INSEE databases, Political is retrieved from Internet (websites of départements), and Listed is retrieved from general company information.

The upper part of the table comprises continuous variables while the lower part comprises categorical variables.

Variable definitions can be found in Table 2. 
Table 4. Estimation Results - Stochastic Frontier Analysis of the Cost Model

\begin{tabular}{|c|c|c|}
\hline \multicolumn{3}{|c|}{ Dependent Variable: InCOSTS } \\
\hline & Coeff. & (St. Errors) \\
\hline \multicolumn{3}{|c|}{ Cost Frontier } \\
\hline ResidentDays & $0.110 * * *$ & $(0.005)$ \\
\hline ResidentDays $^{2}$ & $-0.001 * * *$ & $(0.000)$ \\
\hline Wages $_{N}$ & -0.015 & $(0.072)$ \\
\hline Wages $_{N A}$ & $0.287 * *$ & $(0.139)$ \\
\hline Wages $_{S S}$ & $0.280 * *$ & $(0.126)$ \\
\hline$\%$ RUG1 & Ref & ref \\
\hline$\%$ RUG2 & -0.133 & $(0.095)$ \\
\hline$\%$ RUG3 & $-0.208^{*}$ & $(0.116)$ \\
\hline$\%$ RUG4 & $-0.395 * * *$ & $(0.105)$ \\
\hline$\%$ RUG5 & -0.292 & $(0.222)$ \\
\hline \%RUG6 & $-0.422 * *$ & $(0.184)$ \\
\hline PartiallyRegulated & 0.007 & $(0.019)$ \\
\hline Drugstore & -0.045 & $(0.063)$ \\
\hline PriceOption $=$ global & 0.027 & $(0.022)$ \\
\hline ActivityLength & -0.001 & $(0.001)$ \\
\hline ActivityLength $^{2}$ & 0.00002 & $(0.000)$ \\
\hline BuildOwn = owner & $-0.038 * *$ & $(0.016)$ \\
\hline Attract & 0.025 & $(0.092)$ \\
\hline Urb: inhab $<20,000$ & Ref & ref \\
\hline Urb: $20,000 \leq$ inhab $<200,000$ & 0.010 & $(0.024)$ \\
\hline Urb: $200,000 \leq$ inhab $<500,000$ & $0.076 * * *$ & $(0.028)$ \\
\hline Urb: $500,000 \leq$ inhab $<1,000,000$ & $0.107 * * *$ & $(0.023)$ \\
\hline Urb: Paris & $0.185 * * *$ & $(0.029)$ \\
\hline \multicolumn{3}{|l|}{ Quality variables } \\
\hline Comfort & $0.002 * * *$ & $(0.001)$ \\
\hline$\%$ HighSkill & 0.122 & $(0.096)$ \\
\hline \%MediumSkill & $0.160 * * *$ & $(0.048)$ \\
\hline Staff: $N / N^{*}<0.6$ & Ref & ref \\
\hline Staff: $0.6 \leq N / N^{*}<0.75$ & $0.074 * * *$ & $(0.020)$ \\
\hline Staff: $0.75 \leq N / N^{*}<0.95$ & $0.119 * * *$ & $(0.026)$ \\
\hline Staff: $0.95 \leq N / N^{*}$ & $0.357 * * *$ & $(0.055)$ \\
\hline$\alpha_{0}$ & 0.203 & $(1.102)$ \\
\hline \multicolumn{3}{|c|}{ Inefficiency Analysis } \\
\hline Group $=$ no & Ref & ref \\
\hline Group $=$ medium & $0.304^{*}$ & $(0.155)$ \\
\hline Group = large & $3.193 * * *$ & $(1.108)$ \\
\hline$\delta_{0}$ & $-6.115^{* *}$ & $(2.384)$ \\
\hline$\sigma^{2}$ & $0.566^{* * *}$ & $(0.204)$ \\
\hline$\Gamma$ & $0.980 * * *$ & $(0.009)$ \\
\hline N. & 370 & \\
\hline
\end{tabular}

Note: The upper part of this table presents the coefficient estimates associated with the independent variables of the following cost model estimated by stochastic frontier analysis:

$\ln$ COSTS $=\alpha_{0}+\alpha_{R D}$ ResidentDays $+\alpha_{R D^{2}}$ ResidentDays ${ }^{2}+\sum_{i} \alpha_{w_{i}} \ln \left(\right.$ Wages $\left._{i}\right)+\sum_{k} \alpha_{z_{k}} z_{k}+u_{e}+v_{e}$. The lower part of this table presents the results of the inefficiency analysis (i.e. the regression of the inefficiency term $\left(u_{e}\right)$ on the Group variable with a one-step stochastic frontier analysis approach (Battese \& Coelli, 1995)) to test H1.

Variable definitions can be found in Table 2.

Standard errors are in parentheses.

$\delta_{0}$ is the coefficient associated with the constant of the inefficiency analysis.

$\sigma^{2}$ is the variance of the residual term $\left(u_{e}+v_{e}\right)$.

$\gamma$ is the ratio of the variances of inefficiency $\left(u_{e}\right)$ and residual terms $\left(u_{e}+v_{e}\right)$. 
* Statistical significance at the $10 \%$ level.

** Statistical significance at the 5\% level.

*** Statistical significance at the $1 \%$ level. 
Table 5. Estimated and Actual Costs per Resident-day

Panel A - Mean Comparison of Estimated Costs and Actual Costs per Resident-day

\begin{tabular}{lcccc}
\hline & Group $=$ no & Group $=$ medium & Group $=$ large & Total \\
\hline Mean (estimated costs/resident-days) & 97.0 & 98.8 & 99.3 & 97.7 \\
Mean (actual costs/resident-days) & 106.8 & 109.3 & 121.3 & 109.5 \\
\hline N. & 237 & 77 & 56 & 370 \\
\hline
\end{tabular}

Panel B - Mean Comparison Tests on Estimated Costs per Resident-day

\begin{tabular}{lcc}
\hline & $t$ & More costly \\
\hline Group $=$ no against Group $=$ medium & -1.44 & Group = medium* \\
Group $=$ no against Group $=$ large & -1.25 & Not significantly different \\
Group $=$ medium against Group = large & -0.27 & Not significantly different \\
\hline
\end{tabular}

\section{Panel C - Mean Comparison Tests on Actual Costs per Resident-day}

\begin{tabular}{lcc}
\hline & $t$ & \multicolumn{2}{c}{ More costly } \\
\hline Group $=$ no against Group $=$ medium & -0.97 & Not significantly different \\
Group $=$ no against Group $=$ large & -4.00 & Group $=$ large*** \\
Group $=$ medium against Group $=$ large & -2.94 & Group $=$ large*** \\
\hline
\end{tabular}

Note: This table presents estimated costs and actual costs per resident-day (Panel A), mean comparison tests on estimated costs (Panel B), and mean comparison tests on actual costs (Panel C).

Panel A: Estimated costs are computed by stochastic frontier analysis of the cost model (see Table 4). Actual costs are retrieved from the DIANE database. Data is expressed in $€$.

Variable definitions can be found in Table 2.

* Statistical significance at the $10 \%$ level.

$* *$ Statistical significance at the 5\% level.

$* * *$ Statistical significance at the $1 \%$ level. 
Table 7. Impacts of Local Government, Shareholders, and Market Pressures

\begin{tabular}{lcccccccc}
\hline \multicolumn{7}{c}{ Dependent Variable: Cost Inefficiency $\left(\boldsymbol{u}_{\boldsymbol{e}}\right)$} \\
& \multicolumn{2}{c}{ (c) } & \multicolumn{2}{c}{ (d) } \\
& Coeff. & (St. Err.) & Coeff. & (St. Err.) & Coeff. & (St. Err.) & Coeff. & (St. Err.) \\
\hline Group = no & Ref & ref & Ref & ref & ref & ref & ref & ref \\
Group = medium & $0.342^{*}$ & $(0.197)$ & 0.097 & $(0.090)$ & $0.250^{*}$ & $(0.136)$ & 0.117 & $(0.089)$ \\
Group = large & $2.280^{* *}$ & $(1.127)$ & $1.182^{* * *}$ & $(0.431)$ & $2.218^{* * *}$ & $(0.801)$ & $0.807^{* * *}$ & $(0.210)$ \\
ElderlyExp & $1.645^{* *}$ & $(0.718)$ & - & - & - & - & $0.408^{* *}$ & $(0.186)$ \\
Political = right & $0.821^{* *}$ & $(0.396)$ & - & - & - & - & $0.220^{* *}$ & $(0.085)$ \\
Listed & - & - & $-1.840^{* *}$ & $(0.801)$ & - & - & $-1.113^{* * *}$ & $(0.385)$ \\
MarketShare & - & - & - & - & $-3.158^{* * *}$ & $(1.301)$ & -1.413 & $(1.047)$ \\
$\delta_{0}$ & $-6.521^{*}$ & $(3.472)$ & $-1.629^{* *}$ & $(0.763)$ & $-3.483^{* *}$ & $(1.487)$ & $-1.398^{* * *}$ & $(0.461)$ \\
\hline N. & 370 & \multicolumn{7}{c}{370} \\
\hline
\end{tabular}

Note: This table presents the impacts of chain size, local government pressure (H2), shareholders pressure (H3), and market pressure (H4) on estimated inefficiency term $u_{e} . u_{e}$ and coefficients are estimated by one-step stochastic frontier analysis approach (Battese \& Coelli, 1995).

$\delta_{0}$ is the coefficient associated with the constant of the inefficiency analysis.

Standard errors are in parentheses.

Variable definitions can be found in Table 2.

* Statistical significance at the $10 \%$ level.

** Statistical significance at the $5 \%$ level.

*** Statistical significance at the $1 \%$ level. 
Table 8. Robustness Tests: Quantile Regressions (10\%, 20\%), SFA with a Continuous Group Variable, Dependent Variable with Addition of Interest Expenses, and Replacement of ActivityLength by BuildAge

\begin{tabular}{|c|c|c|c|c|c|c|c|c|c|c|}
\hline \multicolumn{11}{|c|}{ Dependent Variable: InCOSTS } \\
\hline & \multicolumn{2}{|c|}{$\mathrm{QR}(20 \%)$} & \multicolumn{2}{|c|}{$\mathrm{QR}(10 \%)$} & \multicolumn{2}{|c|}{ SFA - continuous Group var. } & \multicolumn{2}{|c|}{ SFA - with COSTSbis } & \multicolumn{2}{|c|}{ SFA - with BuildAge } \\
\hline & Coeff. & (St. Err.) & Coeff. & (St. Err.) & Coeff. & (St. Err.) & Coeff. & (St. Err.) & Coeff. & (St. Err.) \\
\hline \multicolumn{11}{|c|}{ Cost Frontier } \\
\hline Resident Days & $0.113^{* * *}$ & $(0.004)$ & $0.116^{* * *}$ & $(0.020)$ & $0.110^{* * *}$ & $(0.005)$ & $0.110^{* * *}$ & $(0.005)$ & $0.110^{* * *}$ & $(0.005)$ \\
\hline Resident Days ${ }^{2}$ & $-0.001 * * *$ & $(0.000)$ & $-0.002 * * *$ & $(0.000)$ & $-0.001 * * *$ & $(0.000)$ & $-0.001 * * *$ & $(0.000)$ & $-0.001 * * *$ & $(0.000)$ \\
\hline Wages $N_{N}$ & $0.101^{*}$ & $(0.059)$ & 0.064 & $(0.250)$ & -0.019 & $(0.071)$ & -0.007 & $(0.072)$ & -0.015 & $(0.072)$ \\
\hline Wages $_{N A}$ & 0.089 & $(0.092)$ & 0.179 & $(0.444)$ & $0.270^{*}$ & $(0.143)$ & $0.275^{*}$ & $(0.141)$ & $0.280 * *$ & $(0.135)$ \\
\hline Wagess $s$ & $0.195 *$ & $(0.109)$ & 0.281 & $(0.534)$ & $0.274 * *$ & $(0.127)$ & $0.260 * *$ & $(0.128)$ & $0.281 * *$ & $(0.125)$ \\
\hline \%RUG1 & ref & ref & ref & ref & ref & ref & ref & ref & ref & ref \\
\hline \%RUG2 & $-0.147 * *$ & $(0.070)$ & -0.180 & $(0.292)$ & -0.135 & $(0.094)$ & -0.145 & $(0.095)$ & -0.125 & $(0.095)$ \\
\hline$\%$ RUG3 & $-0.266 * * *$ & $(0.084)$ & -0.250 & $(0.445)$ & $-0.202 *$ & $(0.113)$ & $-0.215^{*}$ & $(0.117)$ & $-0.202 *$ & $(0.116)$ \\
\hline \%RUG4 & $-0.373 * * *$ & $(0.075)$ & -0.467 & $(0.343)$ & $-0.393 * * *$ & $(0.104)$ & $-0.397 * * *$ & $(0.106)$ & $-0.374 * * *$ & $(0.105)$ \\
\hline \%RUG5 & -0.157 & $(0.177)$ & -0.716 & (1.012) & -0.307 & $(0.225)$ & -0.294 & $(0.222)$ & -0.294 & $(0.224)$ \\
\hline \%RUG6 & $-0.238 * *$ & $(0.119)$ & -0.195 & $(0.615)$ & $-0.411 * *$ & $(0.183)$ & $-0.431 * *$ & $(0.184)$ & $-0.415 * *$ & $(0.185)$ \\
\hline PartiallyRegulated & 0.009 & $(0.013)$ & 0.015 & $(0.060)$ & 0.007 & $(0.019)$ & 0.005 & $(0.019)$ & 0.009 & $(0.019)$ \\
\hline Drugstore & 0.008 & $(0.051)$ & -0.061 & $(0.101)$ & -0.047 & $(0.063)$ & -0.036 & $(0.063)$ & -0.039 & $(0.063)$ \\
\hline PriceOption $=$ global & $0.065^{* * *}$ & $(0.015)$ & 0.065 & $(0.065)$ & 0.028 & $(0.022)$ & 0.026 & $(0.022)$ & 0.024 & $(0.022)$ \\
\hline ActivityLength & -0.001 & $(0.001)$ & -0.003 & $(0.005)$ & -0.001 & $(0.001)$ & -0.001 & $(0.001)$ & - & - \\
\hline ActivityLength $^{2}$ & $0.00002 * *$ & $(0.000)$ & 0.00002 & $(0.000)$ & 0.00002 & $(0.000)$ & 0.00002 & $(0.000)$ & - & - \\
\hline BuildAge & - & - & - & - & - & - & - & - & 0.001 & $(0.001)$ \\
\hline BuildAge $^{2}$ & - & - & - & - & - & - & - & - & -0.000004 & $(0.000)$ \\
\hline BuildOwn = owner & -0.012 & $(0.011)$ & -0.011 & $(0.054)$ & $-0.037 * *$ & $(0.016)$ & $-0.034 * *$ & $(0.016)$ & $-0.036^{* *}$ & $(0.016)$ \\
\hline Attract & $0.112 * *$ & $(0.047)$ & 0.083 & $(0.260)$ & 0.028 & $(0.089)$ & 0.023 & $(0.091)$ & 0.041 & $(0.088)$ \\
\hline Urb: inhab $<20,000$ & ref & ref & ref & ref & ref & ref & ref & ref & ref & ref \\
\hline Urb: $20,000 \leq$ inhab $<200,000$ & 0.026 & $(0.017)$ & 0.043 & $(0.087)$ & 0.010 & $(0.024)$ & 0.005 & $(0.024)$ & 0.008 & $(0.024)$ \\
\hline Urb: $200,000 \leq$ inhab $<500,000$ & $0.107 * * *$ & $(0.021)$ & 0.111 & $(0.096)$ & $0.074 * * *$ & $(0.028)$ & $0.069^{* *}$ & $(0.028)$ & $0.075^{* * *}$ & $(0.028)$ \\
\hline Urb: $500,000 \leq$ inhab $<1,000,000$ & $0.091 * * *$ & $(0.018)$ & 0.104 & $(0.083)$ & $0.108^{* * *}$ & $(0.023)$ & $0.104 * * *$ & $(0.023)$ & $0.107 * * *$ & $(0.023)$ \\
\hline Urb: Paris & $0.187 * * *$ & $(0.023)$ & $0.229^{* *}$ & $(0.099)$ & $0.185^{* * *}$ & $(0.029)$ & $0.183 * * *$ & $(0.029)$ & $0.196^{* * *}$ & $(0.029)$ \\
\hline \multicolumn{11}{|l|}{ Quality variables } \\
\hline Comfort & $0.003 * * *$ & $(0.000)$ & 0.002 & $(0.003)$ & $0.002 * * *$ & $(0.001)$ & $0.002 * * *$ & $(0.001)$ & $0.002 * * *$ & $(0.001)$ \\
\hline$\%$ HighSkill & $0.147 * *$ & $(0.067)$ & 0.242 & $(0.213)$ & 0.126 & $(0.095)$ & 0.121 & $(0.095)$ & 0.127 & $(0.095)$ \\
\hline$\%$ MediumSkill & $0.130 * * *$ & $(0.035)$ & 0.160 & $(0.179)$ & $0.160 * * *$ & $(0.048)$ & $0.163 * * *$ & $(0.048)$ & $0.152 * * *$ & $(0.048)$ \\
\hline Staff: $N / N^{*}<0.6$ & ref & ref & ref & ref & ref & ref & ref & ref & ref & ref \\
\hline Staff: $0.6 \leq N / N^{*}<0.75$ & $0.065 * * *$ & $(0.015)$ & 0.083 & $(0.069)$ & $0.073 * * *$ & $(0.021)$ & $0.076^{* * *}$ & $(0.020)$ & $0.077 * * *$ & $(0.021)$ \\
\hline Staff: $0.75 \leq N / N^{*}<0.95$ & $0.113 * * *$ & $(0.018)$ & 0.087 & $(0.074)$ & $0.118^{* * *}$ & $(0.026)$ & $0.119 * * *$ & $(0.026)$ & $0.119 * * *$ & $(0.026)$ \\
\hline Staff: $0.95 \leq N / N^{*}$ & $0.345 * * *$ & $(0.037)$ & $0.397 * * *$ & $(0.138)$ & $0.358^{* * *}$ & $(0.055)$ & $0.368 * * *$ & $(0.055)$ & $0.352 * * *$ & $(0.056)$ \\
\hline$\alpha_{0}$ & 1.681 & $(1.296)$ & 0.328 & $(5.113)$ & 0.483 & $(1.276)$ & 0.444 & $(1.144)$ & 0.188 & $(1.005)$ \\
\hline \multicolumn{11}{|c|}{ Inefficiency Analysis } \\
\hline Group $=$ no & ref & ref & ref & ref & - & - & ref & ref & ref & ref \\
\hline Group $=$ medium & 0.004 & $(0.023)$ & 0.005 & $(0.022)$ & - & - & $0.893 * *$ & $(0.453)$ & $0.685^{*}$ & $(0.362)$ \\
\hline Group $=$ large & $0.108 * * *$ & $(0.025)$ & $0.092 * * *$ & $(0.025)$ & - & - & $3.145 * *$ & (1.442) & $3.169 * *$ & $(1.440)$ \\
\hline Group (continuous var.) & - & - & - & - & $0.020 * *$ & $(0.009)$ & - & - & - & - \\
\hline$\delta_{0}$ & $0.086^{* * *}$ & $(0.011)$ & $0.134 * * *$ & $(0.011)$ & $-5.789 * *$ & $(2.821)$ & $-5.984 *$ & $(3.061)$ & $-6.067 *$ & $(3.099)$ \\
\hline Pseudo $\mathrm{R}^{2}$ & 0.7437 & & 0.7490 & & - & - & - & - & - & - \\
\hline$\sigma^{2}$ & - & - & - & - & $0.511 * *$ & $(0.234)$ & $0.551 * *$ & $(0.261)$ & $0.556 * *$ & $(0.262)$ \\
\hline$\gamma$ & - & - & - & - & $0.976^{* * *}$ & $(0.014)$ & $0.979 * * *$ & $(0.012)$ & $0.979 * * *$ & $(0.010)$ \\
\hline $\mathrm{N}$. & 370 & & 370 & & 370 & & 370 & & 370 & \\
\hline
\end{tabular}


Note: This table presents different robustness checks.

Variable definitions can be found in Table 2.

QR $(20 \%)$ and QR(10\%) correspond to another estimation method than SFA: quantile regression computed with 20th percentile and 10th percentile thresholds respectively.

In SFA - continuous Group var., the categorical Group variable is replaced by a continuous Group variable computed as the total number of nursing homes included in the chain.

In SFA - with COSTSbis, the dependent COSTS variable is replaced by COSTSbis defined as the sum of operational expenses and interest expenses.

In SFA - with BuildAge, the independent variable ActivityLength is replaced by BuildAge defined as the number of years since the latest renovation (if not, we use construction) of the building.

Standard errors are in parentheses.

$\delta_{0}$ is the coefficient associated with the constant of the inefficiency analysis.

$\sigma^{2}$ is the variance of the residual term $\left(u_{e}+v_{e}\right)$.

$\gamma$ is the ratio of the variances of inefficiency $\left(u_{e}\right)$ and residual terms $\left(u_{e}+v_{e}\right)$.

* Statistical significance at the $10 \%$ level.

** Statistical significance at the $5 \%$ level.

*** Statistical significance at the $1 \%$ level. 